\title{
The mouse "xenotropic" gammaretroviruses and their XPR1 receptor
}

\author{
Christine A Kozak
}

\begin{abstract}
The xenotropic/polytropic subgroup of mouse leukemia viruses (MLVs) all rely on the XPR1 receptor for entry, but these viruses vary in tropism, distribution among wild and laboratory mice, pathogenicity, strategies used for transmission, and sensitivity to host restriction factors. Most, but not all, isolates have typical xenotropic or polytropic host range, and these two MLV tropism types have now been detected in humans as viral sequences or as infectious virus, termed XMRV, or xenotropic murine leukemia virus-related virus. The mouse xenotropic MLVs (X-MLVs) were originally defined by their inability to infect cells of their natural mouse hosts. It is now clear, however, that X-MLVs actually have the broadest host range of the MLVs. Nearly all nonrodent mammals are susceptible to XMLVs, and all species of wild mice and several common strains of laboratory mice are X-MLV susceptible. The polytropic MLVs, named for their apparent broad host range, show a more limited host range than the X-MLVs in that they fail to infect cells of many mouse species as well as many nonrodent mammals. The co-evolution of these viruses with their receptor and other host factors that affect their replication has produced a heterogeneous group of viruses capable of inducing various diseases, as well as endogenized viral genomes, some of which have been domesticated by their hosts to serve in antiviral defense.
\end{abstract}

\section{Introduction}

Gammaretroviruses of three distinct host range tropisms have been isolated from the laboratory mouse (Table 1). The first of these mouse leukemia viruses (MLVs) were discovered in 1951 through their association with neoplasias of hematopoietic origin [1]. These MLVs were found to infect mouse and rat cells and could induce leukemias or lymphomas in inoculated mice. A second MLV type with a distinctly different host range was subsequently isolated by Levy and Pincus from the NZB mouse strain [2]. These viruses were defined by their apparent inability to infect cells of their host species, although they could efficiently infect cells of other species such as human, rabbit and cat $[3,4]$. These viruses were termed xenotropic (Gr. Xenos - foreign) to distinguish them from the mouse-tropic, sometimes pathogenic MLVs, now termed ecotropic (Gr. Oikos, home), that is, viruses with host range limited to the species of origin $[5,6]$. The third MLV host range group, the polytropic or dualtropic viruses (P-MLVs), are routinely isolated from mouse lymphomas and leukemias, and were

Correspondence: ckozak@niaid.nih.gov

Laboratory of Molecular Microbiology, National Institute of Allergy and Infectious Diseases, Bethesda, MD 20892-0460, USA initially described as having the broadest host range of the $3 \mathrm{MLV}$ types because they could efficiently infect mouse cells as well as cells of heterologous species $[7,8]$. The P-MLVs can be pathogenic in mice and cytopathic in mink cells and have also been termed mink cell focus-forming (MCF) MLVs.

The host range of these 3 MLV subtypes maps to the receptor binding domains (RBDs) of their envelope (Env) glycoproteins, and their RBDs govern the ability of these viruses to interact with their cognate receptors [9-11]. While the E-MLVs use the mCAT-1 receptor for entry [12], the X-MLVs and P-MLVs both use the XPR1 receptor [13-15] (Table 1) and I will term the set of mouse viruses that use this receptor, X/P-MLVs. Host range differences among the $\mathrm{X} / \mathrm{P}-\mathrm{MLVs}$ are due to sequence polymorphisms in the viral env and in the host receptor gene. These genes evolved in concert, altering virus-receptor interactions and the biological properties of these viruses, and producing an unusually heterogenous set of retrovirus and receptor variants.

Analysis of X/P-MLVs in laboratory and wild mice has detailed their roles in pathogenesis, their acquisition as endogenous elements in the Mus genome, and their interactions with and co-option as host restriction 
Table 1 Classically defined host range subgroups of infectious mouse gammaretroviruses isolated from laboratory mice

\begin{tabular}{|c|c|c|c|c|c|c|c|}
\hline \multirow[b]{2}{*}{ Type } & \multirow[b]{2}{*}{ Subtype } & \multirow[b]{2}{*}{ Tropism } & \multicolumn{2}{|c|}{ Host Range } & \multirow[b]{2}{*}{ Receptor } & \multirow[b]{2}{*}{$\begin{array}{c}\text { Pathogenicity in Laboratory } \\
\text { Mice }\end{array}$} & \multirow[b]{2}{*}{$\begin{array}{l}\text { Endogenous } \\
\text { Retroviruses }\end{array}$} \\
\hline & & & $\begin{array}{l}\text { Laboratory } \\
\text { Mouse }\end{array}$ & $\begin{array}{c}\text { Other } \\
\text { Mammals }\end{array}$ & & & \\
\hline E-MLV & & ecotropic & + & - & mCAT-1 &,+- & Emv \\
\hline \multirow{2}{*}{$\begin{array}{l}\text { X/P- } \\
\text { MLV }\end{array}$} & X-MLV & xenotropic & - & + & XPR1 & - & $X m v$ \\
\hline & P-MLV & polytropic & + & + & XPR1 &,+- & M/Pmv (Pmv, Mpmv) \\
\hline
\end{tabular}

factors. This review will describe the evolutionary history of these viruses with special emphasis on tropism changes, the involvement of these viruses in disease induction in mice, and host factors that affect their replication and their recent transspecies transmission to humans.

\section{Endogenous MLVs in Laboratory Mice}

Approximately $37 \%$ of the Mus genome is comprised of retroelements, and one-third of these are endogenous retroviruses (ERVs) $[16,17]$. ERVs represent germline proviral insertions generated by past retroviral infections. While the Class I ERVs that include the MLV ERVs constitute less than 1\% of the mouse genome, attention has focused on this relatively small subgroup because of their relationship to the infectious and pathogenic C-type gammaretroviruses.

The MLVs and their endogenous ERV counterparts have the simplest of retrovirus genomes [18]. The MLV ERV genomes contain protein coding sequences for the virus core proteins ( $(\mathrm{ag})$ ), enzymes ( $\mathrm{pro}, \mathrm{pol}$, in) and envelope (env) that are flanked by long terminal repeat sequences (LTRs) that regulate transcription. The gammaretroviruses lack the accessory proteins of immunodeficiency viruses like HIV-1, have only one zinc-finger in nucleocapsid and rely on a translational strategy that reads through the gag termination codon. Many gammaretroviruses also uniquely produce a second, larger and glycosylated form of the Gag precursor polyprotein that uses an alternate, upstream initiation codon [19-21].

All three host-range MLV variants are present as ERVs in laboratory mice, many of which are full-length, with apparently nondefective protein-coding regions. Infectious viruses of all three host range classes can be isolated from mice, but not all ERVs produce virus, and those that do differ significantly in the timing and circumstances of their expression. Chromosomal locations for many of these ERVs in common inbred mouse strains were determined by conventional genetic methods [22-24] and the completion of the mouse genome sequence has allowed for complete characterization of the ERVs carried by the C57BL mouse [25]. ERV locations are, however, strain or strain-lineage specific; the various inbred strains carry multiple non-allelic provirus insertions $[24,26]$.

\section{Ecotropic MLV ERVs (Emvs)}

Many if not most of the Emvs can produce infectious virus. Up to $6 E m v$ s are found in the inbred strains (Table 2) [26]. Some of these Emvs are constitutively expressed from birth in the "high virus" strains such as AKR (Table 2) [27]. Other Emvs are inefficiently expressed, but their expression can be enhanced or induced by halogenated pyrimidines [28,29]; mouse strains carrying these Emvs produce infectious virus late in life, if at all (Table 2). Other mouse strains carry no Emvs [26]. Novel Emv proviruses can be acquired in viremic strains like AKR [30,31]; oocytes are the targets of these germline reinfections [32].

\section{Polytropic MLV ERVs (M/Pmvs)}

There are up to 40 copies of P-MLV ERVs in the laboratory mouse genome $[24,33]$. The P-MLV ERVs have been divided into two closely related subgroups that differ most notably by the presence or absence of a 27-bp segment in the proline rich domain of env. These 2 P-MLV ERV groups are termed polytropic $(P m v s)$ and modified polytropic (Mpmvs or mPTs), and there is a smaller subgroup named intermediate polytropic MLVs (iPT), identified in NFS/N mice [34,35]. I will use the term $M / P m v s$ to refer to this subgroup of MLV ERVs collectively or when subtype is not known. Although the coding regions of many $M / P m v s$ have open reading frames [25], none are apparently capable of producing infectious virus; the reason for this is unknown, but may be due to accumulated mutations [25] or to LTR defects such as the presence of a 190 bp LTR insertion [36].

Despite the apparent inability of $M / P m v s$ to produce infectious virions, cell-to-cell transmission of this subgroup can be detected, and infectious P-MLVs can be produced in the presence of E-MLV infection. Thus, replicating E-MLVs can recombine with $M / P m v$ ERVs in mice to produce recombinant viruses with $M / P m v$ env sequences [35,37-40]; these viruses generally have polytropic host range, but are usually transmitted in viremic mice as pseudotypes of E-MLVs [41,42]. In the 
Table 2 Distribution of active MLV ERVs and their expression in selected common strains of laboratory mice.

\begin{tabular}{|c|c|c|c|}
\hline ERV Type & Expression Level & Laboratory Mouse Strains $^{a}$ & Expressed MLV ERVs \\
\hline & High & $\mathrm{AKR}, \mathrm{C} 58, \mathrm{HRS}, \mathrm{PL}, \mathrm{SL}, \mathrm{F} / \mathrm{St}, \mathrm{C} 3 \mathrm{H} / \mathrm{Fg}$ & 2-6 Emvs/strain \\
\hline \multirow[t]{4}{*}{ Emv } & Intermediate & $\mathrm{BALB} / \mathrm{C}, \mathrm{DBA}, \mathrm{RF}, \mathrm{CBA}, \mathrm{NZW}, \mathrm{C} 57 \mathrm{BR}, \mathrm{C} 57 \mathrm{BL}, \mathrm{C} 3 \mathrm{H} / \mathrm{He}, \mathrm{SJL}$ & 1-2 Emvs/strain \\
\hline & Low & NFS, NIH Swiss, C57L, 129, NZB, SWR & - \\
\hline & High & NZB & NzV2, NZV1 \\
\hline & & $\mathrm{F} / \mathrm{St}$ & Bxv1 \\
\hline \multirow[t]{3}{*}{$x m v$} & & C57BL, C57L, BALB/C, DBA, AKR, NZW, HRS & $B \times v 1$ \\
\hline & & MA/My & $B \times v 1, M \times v 1$ \\
\hline & Negative (Rare?) & NFS, NIH Swiss, A, 129, SWR & - \\
\hline
\end{tabular}

apparent absence of recombination, the transcribed products of $M / P m v s$ can also be packaged as homodimers into virions of exogenous ecotropic virus, and these "mobilized" $M / P m v s$ can infect cells, replicate in those new cells, and spread to other cells as pseudotyped virus [43]. Another transmission mechanism allows P-MLVs to completely bypass the need for their cognate receptor. These viruses are able to use alternative receptors in the presence of the soluble RBD glycoprotein for that receptor. Thus, entry defective E-MLVs as well as PMLVs, but not X-MLVs, can be "transactivated" in this way by E-MLV RBD $[44,45]$.

\section{Xenotropic MLV ERVs (Xmvs)}

$X m \nu$ s are present in 1-20 copies per mouse strain $[33,46]$. The $X m v$ s in the sequenced C57BL genome are highly polymorphic, and phylogenetic analysis suggests that these $X m v$ s fall into 3 clades which may have resulted from 3 separate infections [25]. Some of the laboratory mouse $X m v$ s produce high levels of virus and other $X m v$ s can be induced to produce virus, but most $X m v$ s are not readily capable of producing infectious virus (Table 2). Among the laboratory mice, two strains, $\mathrm{NZB}$ and $\mathrm{F} / \mathrm{St}$, have a high virus phenotype, producing high titers of X-MLV throughout most of their lives $[2,47,48]$. Other strains rarely produce infectious virus, but cells from many common strains can produce virus following chemical induction or stimulation of spleen cells by bacterial lipopolysaccharide (LPS) or in a graft versus host reaction $[28,29,49,50]$.

There are four active proviruses capable of producing virus in laboratory mice (Table 2). One of these proviruses, $B x v 1$, is a Chromosome 1 (Chr 1) locus sensitive to chemical induction or stimulation by LPS [51], and is carried by about one-third of the common strains of inbred mice [52]. The $B x v 1$ provirus has been identified [46,53], and is present in the sequenced C57BL genome [25]. Expression of $B x v 1$ is low except in the F/St strain, where the high level of virus expression is linked to the major histocompatibility locus [54]. The 3 additional active $X m v$ s found in laboratory mice have not been characterized. The high virus NZB mouse carries two loci neither of which maps to Chr 1 [55-57]. Nzv1 produces low levels of X-MLV, but $\mathrm{Nzv2}$ is constitutively active [55]. The fourth active $\mathrm{Xmv}$ was identified in MA/My mice, a strain that also carries $B x v 1$ [57]. Other strains like NFS and SWR carry Xmvs but are rarely or not capable of producing infectious $\mathrm{X}$ MLV [22,33,53] (Table 2).

\section{ERV produced proteins}

Many ERVs produce viral proteins in the absence of infectious virus. Some of these proteins were initially identified as novel antigens on mouse lymphocytes. Two of the most extensively studied of these antigens, $\mathrm{G}_{\mathrm{IX}}$ and XenCSA, are Env glycoprotein determinants $[58,59]$. These determinants can be detected in virus infected cells, and their expression in mice is associated with specific ERVs and is controlled by host genes linked to the major histocompatibility locus and the retrovirus restriction gene $F v 1[54,60,61]$.

\section{MLVs in cell lines and passaged tumors}

The presence of multiple ERVs in the genomes of all laboratory mice can create problems for the use of these animals or established mouse cell lines in research. Many cell lines in common use carry active ERVs, or ERVs that can become active after long term culture of these lines. For example, the macrophage cell line RAW264.7 produces infectious E-MLV and P-MLV [62]. Also, various $\mathrm{L}$ cell derivatives like Clone 929 (ATCC CCL-1) and A9 (ATCC CCL-1.4) express Env glycoprotein and are either poorly infectible or completely resistant to infection by E-MLVs as well as P-MLVs (unpublished observations). Because $X m v$ s like $B x v 1$ can be induced by immune stimuli, including graft versus host reactions and B cell mitogens [49,50], it is not surprising to find infectious X-MLVs in hybridomas, or in tumor cells passed in SCID or nude immunodeficiency mice, as many of the strains carrying these mutations also carry $B x v 1$. 


\section{Distribution of X/P-MLV ERVs in wild mouse species}

The presence of still active MLV ERVs in mice and the positional polymorphism of these loci among inbred mouse strains indicate that all 3 ERV types entered the Mus germline recently. The genus Mus originated 8-12 million years ago (MYA) on the Indian subcontinent, and the 4 Mus subgenera diverged from one another shortly after Mus diverged from other Murinae [63,64] (Figure 1). Among the 40 recognized Mus species, there are 3 commensal species, or house mice, that evolved 0.5-1.0 MYA, and a fourth house mouse population in Japan, M. molossinus, which represents a natural hybrid of $M$. castaneus and M. musculus [65-67]. These house mice have largely nonoverlapping geographical ranges in Eurasia (Figure 2). House mice differ from their freeliving or aboriginal ancestor species in their dependence on man; the house mice can live in houses, barns, warehouses and ships, and they travel wherever humans go [68]. Over the past few centuries, mice of the house mouse species were collected and interbred by hobbyists in Asia and Europe, and animals from these fancy mouse colonies were used to generate the common strains of the laboratory mouse [69,70]. It is also these house mouse species, the mice in closest contact with humans, that carry MLV ERVs.

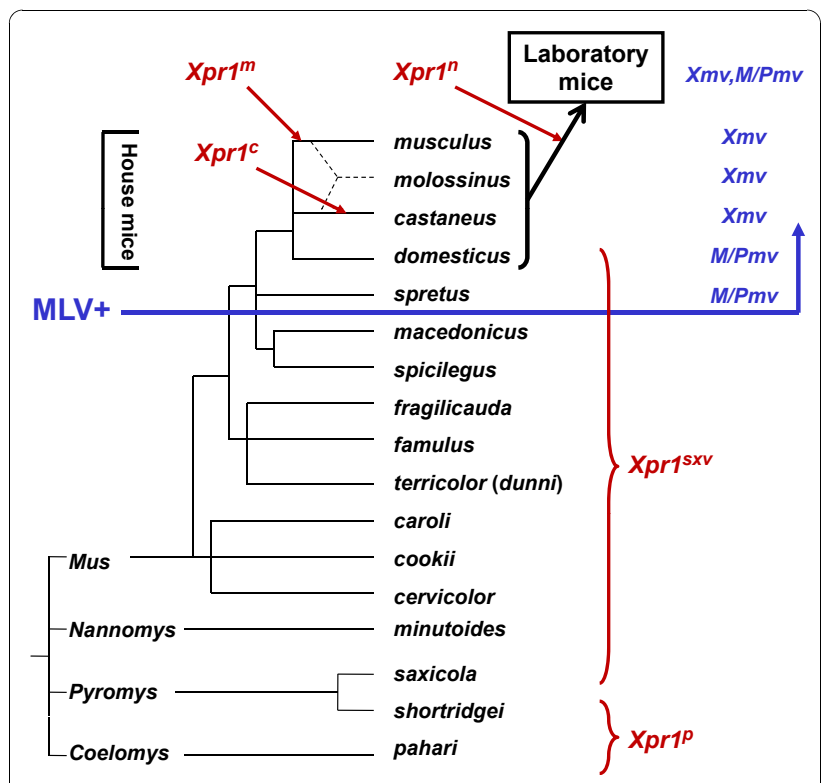

Figure 1 Distribution of Xpr 1 variants and endogenous X/PMLV env genes in the genus Mus. The 4 subgenera originated about 7.5 million years ago (MYA). Red arrows and brackets mark the distribution of the 5 functionally defined Xpr 1 alleles among Mus species and strains. The house mouse species are indicated by a bracket, and the specific MLV ERV env types found in Mus are listed on the right. The tree is adapted from the synthetic trees developed by Guenet and others [63,64,211].

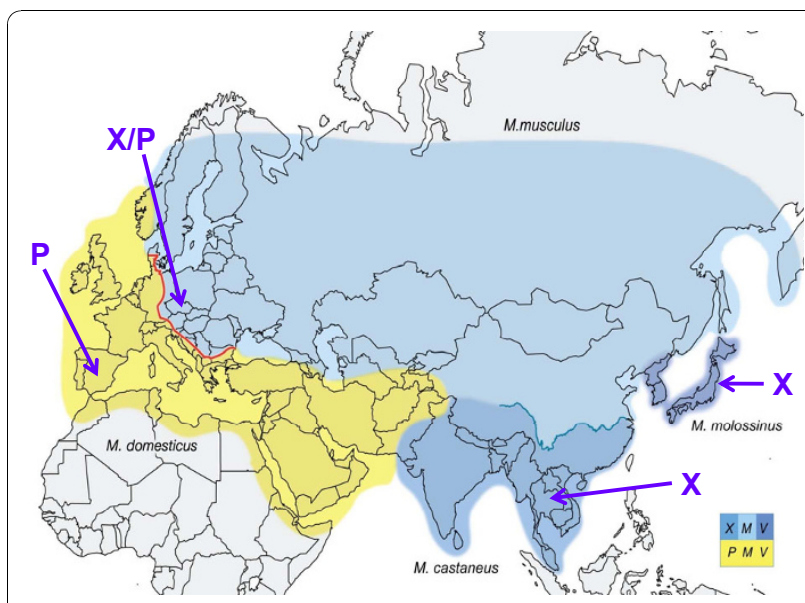

Figure $\mathbf{2}$ Geographic distribution of the $\mathbf{4}$ house mouse species of Mus in Eurasia. The three blue blocks show the distribution of species carrying primarily Xmvs, and the yellow block marks the range of the species carrying M/Pmvs. The blue line is the Yangtze River which roughly coincides with the transition between $M$. castaneus and musculus [66], and the red line represents the wellstudied hybrid zone separating musculus and domesticus [211]. Infectious viruses of the indicated types were isolated from mice trapped at sites indicated with arrows; not shown: the X/P-MLV virus CasE\#1 isolated from a California wild mouse.

The identification of MLV ERV-related env and LTR sequences in house mouse species, but not their freeliving progenitors, suggests these ERVs were acquired only 0.5-1.0 MYA [71]. Although inbred strains of laboratory mice tend to carry multiple copies of both $X m v$ s and $M / P m v s$, these virus subtypes are largely segregated into different species in the house mouse complex [71] (Figure 1, 2 and 3). Sequences related to the env RBD of $M / P m v s$ are found in $M$. domesticus of Western Europe, while Xmvs predominate in $M$. castaneus, M. musculus and M. molossinus in eastern Europe and Asia (Figure 3). Use of probes from the LTR and from env segments that are outside the RBD largely confirmed this pattern of ERV segregation in Mus species, and found two polytropic subtypes, Mpmvs and Pmvs, in M. domesticus as well as evidence of atypical, recombinant types in the various house mouse species [72,73].

Mus is not native to the Americas, but was introduced with human travelers. American house mice most closely resemble the western European $M$. domesticus in that they lack Emvs and carry multiple M/Pmv ERVs and few or no Xmvs [71]. One exception to this is found in Lake Casitas, California, where mice carry multiple copies of Xmvs and M/Pmvs [71]. These mice also carry an Emv subtype common to Asian mice [71,74]. LC mice may thus represent a natural hybrid of European M. domesticus with $M$. castaneus mice that may have arrived in America with Chinese laborers and cargo. 


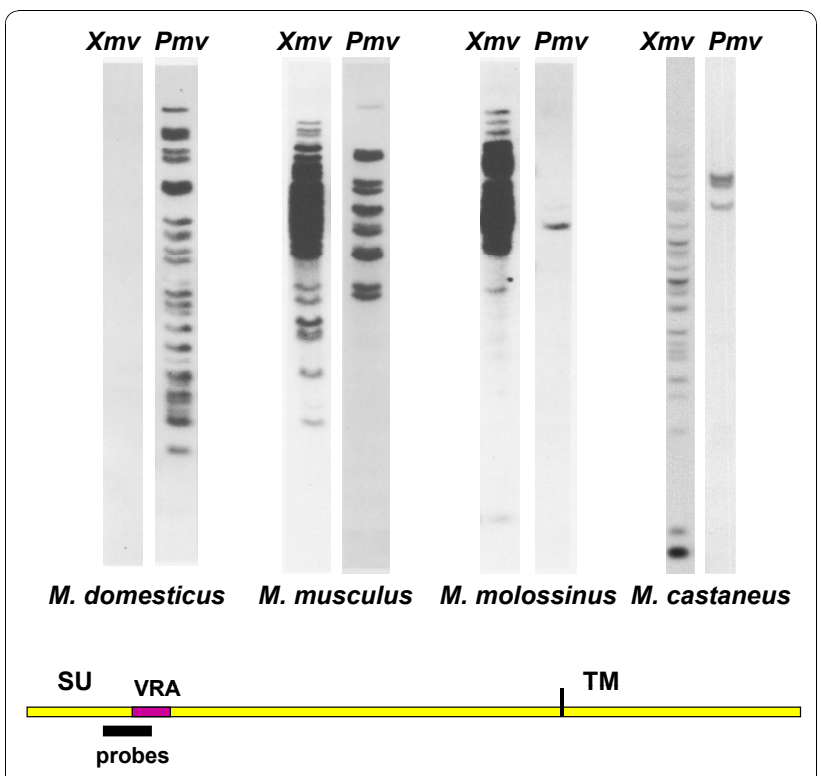

Figure 3 Southern blot analysis of genomic DNAs of house mouse species using env-specific hybridization probes. At the bottom is a diagram of the MLV env showing the position of the $\sim 120$ bp hybridization probes [33,71].

Some of the wild mouse ERVs are active, and infectious viruses of xenotropic or atypical host ranges have been isolated from lymphoid tissues or cultured cells of Eurasian species and from mice trapped in California [57,75-79] (Figure 2). M. molossinus carries multiple ERVs capable of producing X-MLVs [57], one of which has been identified as the active laboratory mouse $B x v 1$ $X m v$ [52]. Bxv1 is found in some, but not all M. molossi$n u s$ breeding lines, but has not been identified in the $X m v$-positive progenitors of $M$. molossinus, M. musculus and $M$. castaneus. This indicates that the $B x v 1$ insertion arose relatively recently in the Japanese $M$. molossinus mice. The presence of Japanese mice among the fancy mouse progenitors of the laboratory strains $[80,81]$ also suggests that these strains acquired $B x v 1$ from Japanese mice. Other wild mouse species, like $M$. dunni and $M$. spretus, carry only $M / P m v s$, and these ERVs, like their laboratory mouse counterparts, do not produce infectious virus. However, M. spretus can, like laboratory mice, produce infectious P-MLVs when inoculated EMLVs recombine with $M / P m v$ ERVs [82].

\section{Heterogeneity among Infectious X/P-MLVs}

Many laboratory and wild mice carry ERVs that can produce infectious MLVs, and some wild mouse populations also carry infectious MLVs that have not become endogenized $[83,84]$. The various X/P-MLVs isolated from laboratory and wild mouse species differ phenotypically on the basis of host range, variable reactivity with antiMLV antibodies, cross-interference, cytopathicity, and pathogenicity in mice. Sequence data for these viruses is limited, but comparisons of available env sequences indicate there is significant heterogeneity, particularly in the RDB of the Env glycoprotein. This region is marked by 3 hypervariable segments, VRA, VRB, VRC, where multiple substitutions and indels distinguish the prototypical PMLVs and X-MLVs. In addition to these sequence polymorphisms, another source of variation comes from the fact that each infectious P-MLV is the product of a recombination between E-MLVs and different endogenous $M / P m v s$, and the size of the recombination can vary $[82,85,86]$.

Not all laboratory mouse P-MLVs have polytropic host range. Some of these recombinant viruses ( $\mathrm{R}-\mathrm{XC}^{-}$, SL3-2, GPA-V2, ecotropic recombinants) have ecotropic host range [9,87-89]. These tropisms are governed by RBD substitutions that lie outside the major host range determinant for MLVs, VRA, which is the most 5' of the 3 variable regions of the $e n v \operatorname{RBD}[9,11,90]$

Among the wild mouse isolates, X-MLVs from $M$. molossinus and M. castaneus, and P-MLVs from $M$. spretus resemble the laboratory mouse isolates in their restriction maps and biological properties [78,91], but $\mathrm{X} / \mathrm{P}-\mathrm{MLVs}$ with atypical host range have also been isolated from wild mice. One such isolate, CasE\#1 (or Cas E No. 1), was isolated from a wild-trapped California mouse [77]. It resembles P-MLVs in its ability to produce MCF-type foci and in its interference properties, but, like X-MLVs, it fails to infect laboratory mouse cells and has novel receptor requirements [77-79]. Cz524 MLV was isolated from the wild derived M. musculus strain CZECHII/EiJ, and differs from both PMLVs and X-MLVs in host range [79]. The env genes of these two wild mouse isolates are not identical to laboratory mouse P-MLVs or X-MLVs, but are related to both $[78,79]$.

\section{XPR1 Receptor for X/P-MLVs}

The X-MLV and P-MLV subgroups use the same XPR1 receptor for entry, although they were initially described as 2 host range groups because of their differential ability to infect mouse cells. This receptor was first identified as a P-MLV susceptibility gene and was mapped to distal Chr 1 [92]. Subsequent studies showed that XMLVs could infect cells derived from wild mice [93-95], and genetic crosses mapped this X-MLV susceptibility as well as the P-MLV resistance of $M$. castaneus to the same segment of distal Chr $1[95,96]$. The conclusion that susceptibility to X-MLVs and P-MLVs is governed by a single gene was also supported by the observations that these viruses cross-interfere [77,97], and that infection by X-MLVs in wild mice is reduced by $R m c f$, a host gene that restricts P-MLV infection by receptor interference [95]. 
The XPR1 receptor for X-MLVs and P-MLVs has 8 putative transmembrane domains and 4 putative extracellular loops [13-15]. This multiple-membrane-spanning structure is a common feature of the receptors used by the gammaretrovirus family [98]. While this suggests these viruses evolved from a common progenitor, this multi-membrane spanning structure is not representative of all retroviral receptors, some of which, like the lentivirus CD4 receptor and the receptors for alpha- and betaretroviruses have single TM domains [99]. Although the host cell function of XPR1 has not been defined, the other gammaretrovirus receptors with known function have all been identified as transporters of small solutes like phosphate or amino acids [98]. The XPR1 protein may have a similar function as it is homologous to the yeast SYG1 and plant PHO1 genes, which have roles in signal transduction and phosphate sensing and transport, respectively [14]. Recent work has indicated that XPR1 is upregulated following activation of the NF- $\kappa$ B RANKL-RANK signaling pathway in osteoclastogenesis [100].

Mus species and inbred strains carry at least 5 functionally distinct XPR1 variants $[13-15,78,95,96,101]$. These five Mus XPR1 s differ in their ability to support entry by prototype X-MLVs and P-MLVs and by the two wild mouse isolates CasE\#1 and Cz524 (Figure 4) $[79,101]$. One of these alleles, $\mathrm{Xpr}^{\text {sxv }}$ (susceptibility to xenotropic virus), is fully permissive for all X/P-MLVs. The other 4 variants restrict infection by two or more members of this virus family. All variants except the XPR1 of NIH 3T3 cells support entry by X-MLVs, although with differences in efficiency. Only 2 of the 5 receptor variants are permissive for P-MLVs. The laboratory mouse allele, $X p r 1^{n}$, allows entry only by PMLVs.

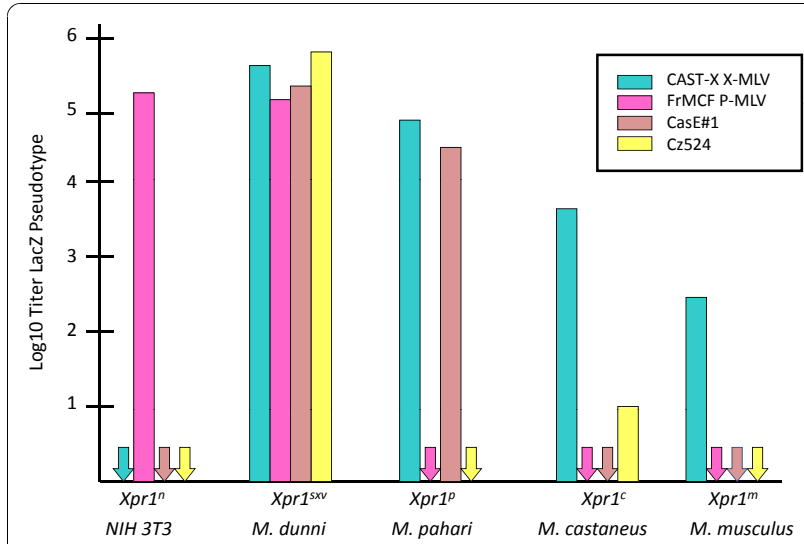

Figure 4 Five functional variants of Xpr1 in Mus. Susceptibility to 4 host range X/P-MLV variants was determined using virus pseudotypes carrying the LacZ reporter gene [101].
Specific XPR1 residues responsible for virus entry lie in 2 of the 4 predicted extracellular loops (ECLs) of Xpr1, ECL3 and ECL4 (Figure 5) [78,79,101-103]. Two critical amino acids are needed for X-MLV entry, K500 in ECL3, and T582 in ECL4 [102]. Both sites are mutated in the X-MLV restrictive NIH 3T3 $X_{p r 1}^{n}$ allele, and corrections at either of these two sites produce XMLV receptors [102], although these are not functionally equivalent. Thus, the $\Delta 582 \mathrm{~T}$ insertion generates a receptor for X-MLV as well as CasE\#1, but the E500K substitution does not allow for CasE\#1 entry [78]. Sensitivity to different $\mathrm{X} / \mathrm{P}-\mathrm{MLVs}$ is further modulated by specific substitutions at ECL3 residues 500, 507, 508 and ECL4 residues 579 and 583 [78,79,101] (Figure 5). Substitutions at these sites can result in subtle differences in the efficiency of virus infection or complete resistance to specific X/P-MLVs.

All of the viruses that use XPR1 are sensitive to mutational changes in both ECL3 and ELC4, suggesting that residues in these ECLs contribute to a single virus attachment site $[78,79,101]$. Thus, Xpr1 mutants with substitutions in ECL3 but identical ECL4 sequences produce receptors with differential sensitivities for P-MLVs and for the CasE\#1 and Cz524 viruses. These same viruses also differ in their infectivity for cells with $X p r 1^{m}, X p r 1^{c}$ and $X p r 1^{s x v}$, which have identical ECL3 sequences but different deletions in ECL4. The

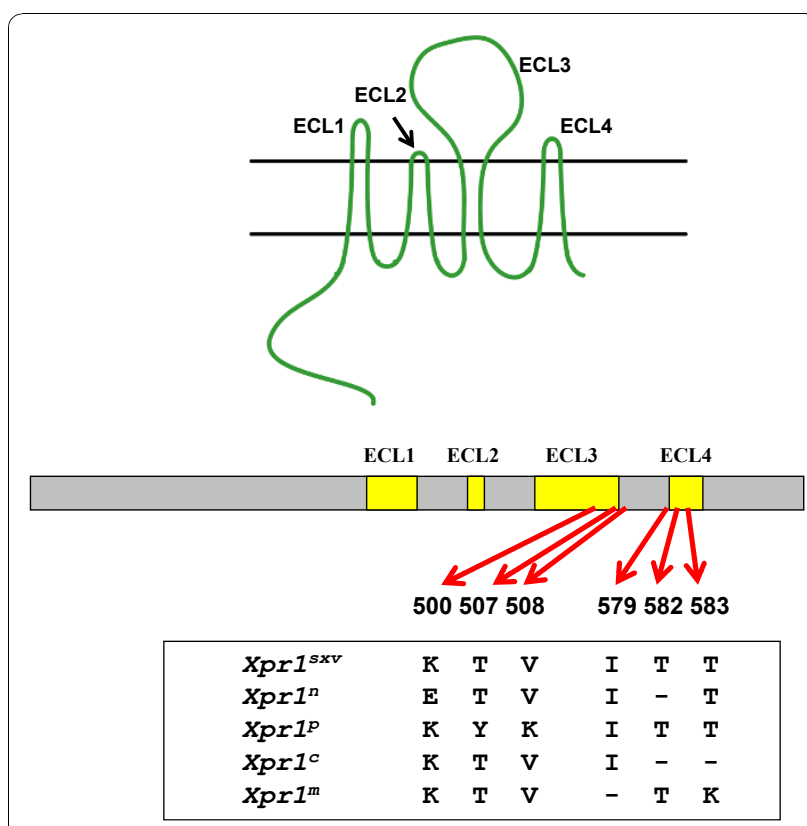

Figure 5 Putative transmembrane structure of XPR1 and locations of the 6 residues responsible for receptor function. XPR1 has 4 putative extracellular loops (top) indicated as yellow bars in the mRNA. Codon positions for residues involved in entry are marked with arrows, and residues at these sites are shown for the 5 Mus alleles. "-" represents a deletion. 
requirement for residues in two XPR1 loops for receptor function is not unusual as other receptors require multiple domains [104]. While these multiple domains in several other retroviral receptors have distinctive roles in virus attachment and entry $[105,106]$, this has not been shown to be the case for the XPR1 ECL3 and ECL4 domains.

\section{Evolution of the Xpr1 receptor gene in virus infected mice}

The 5 functionally distinct mouse XPR1 receptor variants are found in different mouse lineages. The species and geographic distribution of these variants indicate that much of this receptor variation is coincident with exposure to MLVs [101]. Most Mus species carry the most permissive XPR1 variant, $X p r 1^{s x v}$, which persisted in Mus through much of its evolutionary history (Figure 1). The species with $X p r 1^{s x v}$ either lack X/P-MLV ERVs or carry only M/PMV ERVs that are not known to produce infectious virus. The 4 restrictive receptor alleles appeared at two distinct time points in Mus evolution. $X_{p r 1}{ }^{p}$ appeared about 7.5 MYA, shortly after the divergence of Mus from other Murinae [63,64], and there is no evidence that the mice with this restrictive receptor were exposed to MLVs as they lack MLV ERVs [71]. The other 3 restrictive Xprls arose later, in the house mouse complex. This roughly coincides with the acquisition of X/P-MLV ERVs (Figure 1). Two of these 3 restrictive house mouse variants, $X p r 1^{m}$ and $X p r 1^{c}$, like the presence of $X m v$ sequences in these species, show an apparent species-wide distribution [101], suggesting these variants provided a survival advantage.

$X p r 1^{n}$ is the only one of the 5 Mus Xpr 1 alleles to completely restrict X-MLVs, and its species of origin is unclear. This laboratory mouse allele has not been found in any wild mouse [101]. The common inbred strains of the laboratory mouse represent genomic mosaics of the various house mouse species, but $M$. domesticus is the largest contributor $(\sim 92 \%)$ to the inbred mouse genome [69]. The expectation that $M$. domesticus would likely carry $\mathrm{Xpr}^{n}{ }^{n}$ also makes biological sense, as these mice carry endogenous Pmvs but not $X m v s$ consistent with $X p r 1^{n}$ receptor function [71]. However, $M$. domesticus mice trapped at various sites throughout its western European range and in the Americas all carry $X p r 1^{s x v}$ (Figure 6). It is thus possible that $X p r 1^{n}$ arose later, in the fancy mouse progenitors of laboratory mice. These fancy mouse interspecific hybrids would have acquired $M / P m v s$ from domesticus and Xmvs from musculus and castaneus, and a restrictive receptor might have provided a survival advantage for these mice.

Sequence comparisons of Xprl orthologues from Mus and other rodent species indicate that there is

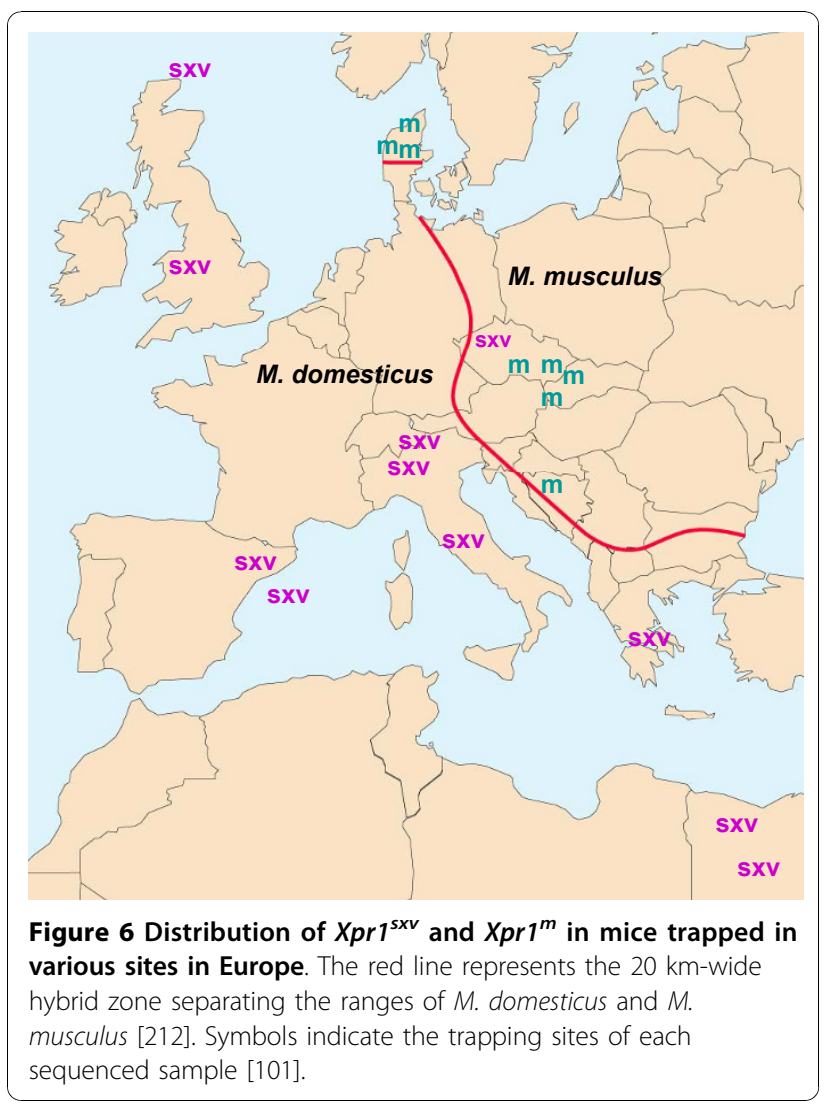

substantial polymorphism in the short, virus-binding 13 residue ECL4. This region contains 3 residues that are conserved in all mammalian XPR1 orthologues, but these residues do not contribute to receptor function [101]. While ECL4 sequence variation is due largely to replacement mutations, the three restrictive alleles found in virus-infected house mice, $X p r 1^{m}, X p r 1^{n}$, $X p r 1^{c}$, all carry deletions in this region (Figure 5) $[101,102]$. The deletions are all different and no deletions in this region are found in other mouse or rodent species, or in any mammalian Xpr1 orthologue. Either the 6 residues involved in these deletions are critical for entry as has been shown for some of them, or decreasing the size of the ECL4 loop may effectively disable receptor function.

\section{XPR1 variants in inbred strains of the laboratory mouse}

The first $X p r 1$ allele to be recognized, $X p r 1^{n}$, was identified in X-MLV resistant laboratory mice, but $X p r 1^{n}$ is not universal among the common inbred strains of laboratory mice. These widely used common strains were developed largely by William Castle and C. C. Little from fancy mice provided by hobbyists, especially Abbie Lathrop [70]. While these Lathrop/Castle/Little strains have a shared ancestry reflected in their reduced 
genetic diversity compared to Mus species [107,108], the various lineages and strains differ in their susceptibility to virus induced disease, and in their ability to produce infectious MLVs or viral proteins (Table 2). While some of these differences can be explained by the presence of ERVs with different levels of activity, receptor variations could also be important factors in these different phenotypes.

While $X p r 1^{n}$ is carried by the majority of laboratory mice, $X p r 1^{s x v}$, which encodes the permissive receptor, has now been identified in several common inbred strains. Cells from these strains can be infected with XMLV [52]. One of the strains carrying $X p r 1^{s x v}, \mathrm{~F} / \mathrm{St}$, is one of the two strains that produce high levels of $X-M L V s$ throughout life (Table 2). The role of the receptor in this phenotype is unclear; however, as F/St viremia requires genes on Chr 17 near the major histocompatibility locus and in the segment of distal Chr 1 which carries the active $X m v$ provirus $B x v 1$, as well as Xpr1 [47,54].

Inbred strains derived from various wild mouse species are available that carry all 4 of the wild mouse Xpr 1 variants as well as $X p r 1^{n}$. These strains can, in principle, be used to determine if receptor-mediated secondary spread affects virus levels in mice carrying active proviruses like Bxv1. These mice can also be used to develop models to describe the time course, tissue tropism and pathogenic consequences of exogenous infection by the different X/P-MLV host range subtypes, and to determine whether receptor variants affect the type of recombinant viruses that appear.

\section{Transspecies transmission and XMRV}

The X/P-MLVs are capable of infecting cells of other species, including humans. In fact, cells of nearly all mammals are permissive to infection by X-MLVs, and a smaller subset of these is also susceptible to P-MLVs $[3,4,77,101]$ (Table 3). The horizontal transfer of infectious MLVs between individuals has been documented in wild mouse populations and in laboratory mice $[109,110]$. MLV-infected house mouse species have a worldwide geographic distribution [111], and are considered important vectors of diseases that infect humans and their livestock [112]. It is therefore not surprising that MLV-related ERVs are found in the genomes of amphibians, reptiles, birds and mammals [113], and that $\mathrm{X} / \mathrm{P}-\mathrm{MLV}$-related viruses and viral sequences have now been reported in humans [114-119].

Infectious virus related to X/P-MLVs has been isolated from human patients with prostate cancer and chronic fatigue syndrome $[115,117,118]$. This virus, termed XMRV (xenotropic murine leukemia virus-related virus), shows close sequence homology with X/P-MLVs [114], uses the XPR1 receptor [115], and has xenotropic
Table 3 Infectivity of X/P-MLVs and XMRV on cells of mammalian species

\begin{tabular}{lccccc}
\hline \multirow{2}{*}{ Cells } & \multicolumn{5}{c}{ Log $_{10}$ Titer* } \\
\cline { 2 - 6 } & $\begin{array}{c}\text { CAST-X } \\
\text { X-MLV }\end{array}$ & XMRV & Cz524 & CasE\#1 & P-MLV \\
\hline M. dunni & +++ & +++ & +++ & +++ & +++ \\
\hline Human 293 & +++ & +++ & +++ & +++ & +++ \\
\hline Monkey COS-1 & +++ & +++ & +++ & +++ & +++ \\
\hline Ferret & +++ & +++ & +++ & +++ & +++ \\
\hline Rabbit SIRC & +++ & ++ & +++ & +++ & ++ \\
\hline Cat CRFK & +++ & +++ & +++ & +++ & +++ \\
\hline Bat Tb-1-Lu & +++ & ++ & +++ & +++ & - \\
\hline Guinea pig JH4 & +++ & ++ & ++ & - & - \\
\hline Goat & +++ & ++ & + & - & - \\
\hline Buffalo & +++ & + & - & - & - \\
\hline Dog MDCK & +++ & ++ & - & - & - \\
\hline Gerbil GeLu & +++ & - & - & - & - \\
\hline Chinese hamster & +++ & - & - & - & - \\
\hline Lec8 & & & & & - \\
\hline
\end{tabular}

*Infectivity measured as the number of $\beta$-galactosidase-positive cells in $50 \mu \mathrm{l}$ of viral pseudotypes carrying the LacZ reporter. $\log _{10}$ titer:,$+++>3 ;++, 2-3$; ,$+ 1-2 ;-, 0-1$. [101]. Hamster Lec8 cells have a glycosylation defect that relieves resistance to some X-MLVs.

host range [79]. The VP62 isolate of XMRV and the sequenced DG75 X-MLV genome [120] show overall $94 \%$ sequence identity [114]. A more complicated picture emerges from sequence comparisons of the XMRV coding and non-coding domains with corresponding regions of X-, P-, and E-MLVs, as well as the active Bxv1 Xmv and a full length Mpmv. While XMRV most closely resembles the X-MLVs in SUenv and LTR, it shows greater identity to $M / P m v s$ in $g a g$ and $p o l$ (Table 4). This, coupled with the recent finding of $M / P m v$ related $e n v$ and glycogag sequences in human blood donors and chronic fatigue patients [119] points out the need for further work to clarify the evolutionary path linking the human and mouse viruses and to describe the epidemiology of this virus family in wild mice [121].

The XMRV virus and X/P-MLV sequences found in humans may have been acquired directly from mice, or after transmission from mice to another species in contact with humans. If there is direct transmission from infected mice, this could be reflected in the geographic distribution of virus and/or receptor type in mice and the worldwide incidence of prostate cancer. Studies have reported very different rates of XMRV detection in prostate cancer patients (reviewed in [122]), and while these differences may have technical explanations, it is also possible that some of these differences are due to geographic differences in exposure to XMRV. The highest rates of prostate cancer are found in the U.S. and lowest rates are found in Asian countries like Japan, India and 
Table 4 Sequence comparisons of coding and non-coding domains of XMRV and 5 full length gammaretrovirus genomes

\begin{tabular}{|c|c|c|c|c|c|c|}
\hline & & DG75 X-MLV AF221065 & Bxv1 Xmv AC115959 & Mpmv1 Pmv AC127565 & MCF1233 P-MLV U13766 & AKV E-MLV J01998 \\
\hline & U5 & 90 & 100 & 90 & 99 & 93 \\
\hline \multirow[t]{4}{*}{ LTR } & $\mathbf{R}$ & 95 & 100 & 96 & 99 & 95 \\
\hline & U3 & 87 & 94 & 85 & 84 & 84 \\
\hline & gag leader & 85 & 86 & 90 & 85 & 85 \\
\hline & MA & 90 & 86 & 98 & 84 & 87 \\
\hline \multirow[t]{4}{*}{ gag } & p12 & 97 & 81 & 99 & 82 & 81 \\
\hline & CA & 99 & 88 & 99 & 89 & 87 \\
\hline & NC & 98 & 96 & 99 & 92 & 92 \\
\hline & PR & 99 & 92 & 99 & 92 & 92 \\
\hline \multirow[t]{2}{*}{ pol } & RT & 94 & 93 & 95 & 92 & 93 \\
\hline & IN & 92 & 93 & 97 & 89 & 86 \\
\hline \multirow[t]{2}{*}{ env } & SU & 94 & 95 & 89 & 90 & $<75$ \\
\hline & TM & 98 & 98 & 98 & 83 & 81 \\
\hline
\end{tabular}

Numbers represent percent identity. DG75 is an X-MLV isolated from the human DG-75 lymphoblastoid line [120], MCF1233 and AKV MLV are infectious viruses isolated from AKR strain mice. Bxv1 is the active endogenous xenotropic ERV found in strains such as C57BL and BALB/c. AKV has a duplicated enhancer in U3 that was not included in the analysis. Mpmv1 is a full-length ERV in the sequenced C57BL genome; it contains a 190 bp LTR insert that was not included in the analysis. GenBank accession numbers are provided for the 5 sequences; comparisons were done with VP62 XMRV NC_007815.

China [123]. Rates in Europe are lowest in Eastern European countries. This distribution generally corresponds to the distribution of $X p r 1$ receptor variants in mouse populations; the most permissive allele, $X p r 1^{s x v}$, is found in high tumor incidence areas, and the most restrictive allele, $X p r 1^{m}$, is found in low tumor areas like Japan and eastern Europe. Mice in low tumor areas of Asia also carry receptor blocking genes [124] further indicating that these mice might be poor candidates for zoonotic transmission to humans. While these observations are suggestive of direct transmission between mice and man, it should also be noted that mice in areas of high tumor incidence are not known to carry infectious X/P-MLVs or expressed MLV ERVs.

The transmission of XMRV to humans was likely accompanied by adaptive changes, and the observed sequence and phenotypic differences of XMRV relative to the X/P-MLVs have focused particular attention on the glycogag leader region, LTR and env. XMRV carries unusual deletions in glycogag, a region that in E-MLV influences virus release and sensitivity to interferon [125] and also inhibits the activity of the host cell antiretroviral factor APOBEC3 [126]. XMRV differs from MLVs in its affinity for and efficient replication in prostate cells, and this has been attributed to the glucocorticoid response element in the XMRV LTR U3 [127-129]. Finally, XMRV has a novel host range and receptor requirements that distinquish it from the mouse $\mathrm{X} / \mathrm{P}$ MLVs. Thus, the XPR1 receptor determining residues K500 and T592 produce equivalent receptors for XMLV but not for XMRV [101]. Also, while the mouse $\mathrm{X}-\mathrm{MLVs}$ are generally able to infect all mammals,
XMRV is uniquely restricted by Chinese hamster and gerbil cells (Table 3 ), a restriction associated with sequence differences in the receptor determining region of Xpr1 ECL4 [101]. These multiple XMRV differences may represent adaptations acquired through contact with humans or with an as yet undiscovered species before transmission to humans.

\section{Pathogenesis by MLVs}

The detection of XMRV and P-MLVs in various human patient groups and in blood donors raises questions about the pathogenic and mutagenic potential of these viruses in humans and concerns about the safety of the blood supply. While the involvement of these viruses in human disease is still under investigation, the MLVs were recognized as disease-inducing agents in mice almost 60 years ago [1]. Although most MLVs are generally non-pathogenic or poorly pathogenic in mice, MLVs can and do cause disease in their natural hosts, and the induction of disease can involve X-MLVs and P-MLVs as well as E-MLVs.

Mouse strains carrying active Emvs, like AKR, HRS, and C58, have a high incidence of spontaneous lymphomas, and mice inoculated with specific MLVs can develop diseases such as lymphocytic leukemia, erythroleukemia, immunodeficiencies, and neurological diseases. The naturally occurring and induced neoplastic diseases are generally induced, following a long latency period, by insertional mutagenesis. In this process, novel virus integrations activate genes involved in growth regulation or inactivate tumor suppressor genes $[130,131]$. The established role of insertional mutagenesis in MLV-induced 
disease prompted the characterization of XMRV insertion sites in human prostate cancers [132]. While no common insertion sites were identified near recognized proto-oncogenes or tumor suppressor genes, XMRV integrations were found near cancer breakpoints, common fragile sites, microRNAs, and cancer-related genes.

In mice, MLV-induced neoplastic disease is often associated with the de novo generation of infectious and pathogenic P-MLVs. The disease process generally begins with the establishment of chronic infection with E-MLVs. These viruses can recombine with $M / P m v s$ and $X m v$ s to generate recombinant infectious virus with $\mathrm{P}-\mathrm{MLV}$ host range and increased virulence $[133,134]$. These P-MLV recombinants can be cytopathic, which is why they were initially termed mink cell focus-forming viruses or MCF MLVs [8]. Although not all virusinduced diseases are accompanied by the generation of P-MLV recombinants, the importance of MCF MLVs in the disease process is supported by the fact that these recombinants are found in lymphoid tissues of preleukemic mice and can be found in tumors as infectious virus and novel integrations [135]. Also, inoculation of neonatal AKR mice with MCF virus accelerates the appearance of thymomas [136], and disease is restricted in mice carrying the $R m c f$ resistance gene that inhibits replication of P-MLV [137] or in mice inoculated with genetically altered viruses that cannot participate in MCF production [138].

The recombinations that generate infectious pathogenic P-MLVs involve at least two segments of the viral genome, env and LTR. The LTR sequences are contributed by the active $X m v, B x v 1[53,139]$, and the LTRs of AKR mouse MCFs have duplicated enhancer regions not found in the endogenous $B x v 1$ proviral sequence [134]. The recombinant env segment in MCF MLVs can vary due to the sequence of the participating $M / P m v$ [35] as well as the size of the recombinant segment. Recombinational breakpoints in the MCF env tend to cluster in 2 segments of the 3' half of SUenv or in the 5' end of TMenv $[82,85,86]$.

The role of the recombinant env genes in the disease process is incompletely defined, but these substitutions can contribute to the target cell specificity and disease type induced by MCF MLVs. The most well-studied example of disease mediated by viral Env is the rapid erythroleukemia induced by Friend SFFV, a replicationdefective MCF-type recombinant. SFFV encodes a unique $52 / 55 \mathrm{kDa}$ Env-related protein that functions as an oncogene and induces disease by activating signal transduction pathways associated with the erythropoetin receptor and the receptor tyrosine kinase Stk [140-142]. For other pathogenic MCF MLVs, Env may support the in vivo progression of tumors by hampering the immune response. In some cases, Env substitutions may facilitate virus evasion of the immune system [143], or the ERVderived env genes expressed in tumors may contribute to a T-cell mediated subversion of immune surveillance that allows for tumor cell proliferation [144,145].

Preleukemic thymuses can contain large amounts of unintegrated MCF MLV DNA resulting from failure to establish superinfection interference $[135,146]$. Such superinfections have been associated with cytopathic killing by other pathogenic retroviruses such as HIV and ALV $[147,148]$, and superinfection by MCF results in lymphocyte depletion in the thymus of infected mice [149]. This depletion may result from endoplasmic reticulum stress induced apoptosis [150]. The ability of MCF MLVs to evade superinfection interference is unusual since other MLVs effectively prevent multiple infections by receptor downregulation. This phenomenon may be explained by two properties of the MCF Env. First, like some other pathogenic retroviruses, MCFs may have lower receptor-binding affinity $[45,102]$. Second, multiple infections can result from the ability of MCFs to use the E-MLV receptor for entry in the presence of soluble E-MLV Env [45].

\section{Host factors that restrict replication of X/P-MLVs and XMRV}

The acquisition of MLV ERVs, the time course and tissue specificity of their expression, and the transmission of these viruses to new hosts are governed by host factors that restrict or enhance virus replication and spread. These host factors include the innate and acquired immune systems, as well as numerous constitutively expressed antiviral factors that inhibit virus replication, many of which were initially identified in studies on the mouse gammaretroviruses. These factors can block or interfere with different stages in the viral life cycle, such as virus entry, uncoating and reverse transcription, integration, assembly and release. For this review, I will focus on the host factors that either specifically target the X/P-MLVs and XMRV, or factors that have been shown to have significant restrictive effects on these viruses (Table 5). Among the antiviral factors that restrict these gamaretroviruses, some, like APOBEC and tetherin/BST2 are broadly antiviral, whereas Fv1 targets only MLVs, while XPR1, LVIF, and the RMCFlike interference genes restrict only X/P-MLVs.

\section{Xpr1 receptor polymorphism and glycosylation blocks to entry}

Receptor polymorphisms can clearly provide an especially effective antiviral defense. As already noted, 4 of the 5 XPR1 receptor variants in Mus restrict two or more viruses in the X/P-MLV family. These restrictions result from deletion mutations or replacements that have been shown to display a pattern of positive 
Table 5 Host restriction factors that inhibit replication of gammaretroviruses

\begin{tabular}{lcccc}
\hline & \multicolumn{5}{c}{ Restriction* } \\
\cline { 2 - 5 } Restriction Factor & X-MLV & P-MLV & XMRV & E-MLV \\
\hline Xpr1 & + & + & + & - \\
\hline Entry: glycosylation & + & - & - & + \\
\hline Lvif & + & + & $?$ & - \\
\hline ERV interference & $?$ & + (Rmcf genes) & $?$ & $+($ Fv4 $)$ \\
\hline Fv1 & + & + & + & + \\
\hline Apobec3 & $-?$ & $+?$ & + & + \\
\hline Tetherin/BST2 & $?$ & $?$ & + & + \\
\hline
\end{tabular}

${ }^{*}+$, infectious virus known to be inhibited; determination of Apobec3 restriction of X/P-MLVs based on mutational patterns found in ERVs [25].

selection suggesting an evolutionary history of genetic conflicts [101]. Furthermore, 3 of the 4 naturally occurring restrictive receptor alleles evolved in virus infected mice, suggesting that these variants provided a survival advantage. Additional restrictive Xpr1 variants are found in non-Mus mammals [101] (Table 3).

Entry can also be blocked by factors that interfere with receptor function. Glycosylation of cellular proteins is associated with resistance to E-MLVs in rodent cells and X-MLVs in Chinese hamster cells [151-153]. The glycosylation block in hamster cells does not affect all $\mathrm{X} / \mathrm{P}-\mathrm{MLVs}$; inhibition of glycosylation relieves resistance to most X-MLVs, but not to P-MLVs or to XMRV [79]. Although the XPR1 protein contains multiple sites for $\mathrm{N}$-linked glycosylation including several in the ECL3 receptor determining region, it is not clear whether the glycosylation entry block affects the receptor or another as yet unidentified glycoprotein.

\section{Leukemia virus inactivating factor (LVIF)}

Mice produce a serum factor, leukemia virus interfering factor (LVIF), that inactivates X-MLVs [154]. This factor is stable when exposed to acid $\mathrm{pH}$, ether, proteases and temperature extremes [155]. LVIF is separable from immunoglobulin, is found in the lipoprotein fraction of serum and is sensitive to antiserum to apolipoproteins $[156,157]$. This factor inactivates X-MLVs and P-MLVs but not E-MLVs or the wild mouse amphotropic MLVs. LVIF is therefore not equivalent to the human serum factor responsible for the complement-mediated lysis of MLVs and other retroviruses $[158,159]$. LVIF is produced by some but not all mouse strains, and genetic crosses between these strains show that LVIF is controlled by a single locus that maps to distal Chr 10 [160]. The gene responsible for this factor has not been identified.

\section{ERVs that interfere with exogenous infection}

The mouse genome contains several resistance genes associated with production of MLV Env glycoproteins that are thought to restrict virus through receptor interference. These genes include Fv4, which blocks E-MLVs [161], and the genes Rmcf and Rmcf2 which restrict X/ P-MLVs and, in the case of $R m c f$, inhibit MCF MLVinduced disease [124,162-164]. Specific ERVs have been mapped to these resistance genes all of which are defective for virus production but have intact env genes: $F v 4$ and Rmcf have major deletions [161,165], and Rmcf2 has a stop codon that prematurely terminates integrase [124]. Fv4, Rcmf, and Rcmf2 reduce or downregulate activity of their cognate receptors, and $F v 4$ additionally has a defect in the fusion peptide of the TMenv, so incorporation of this Env into virions in virus infected cells results in their reduced infectivity [166].

There is evidence of additional receptor blocking genes in $M$. castaneus. Three breeding lines of this species show similar restriction of P-MLV infection. Two of these lines, CAST/Rp and CAST/EiJ, carry Rmcf2. Backcross mice of the third line, CAST/Ncr, show evidence of two unlinked dominant resistance genes (\#resistant/ total $\left.=87 / 123=0.71, \chi^{2}=1.2, \mathrm{p}=0.3\right)$, and neither of these genes maps to Chr 5 (Rmcf) or Chr 18 (Rmcf2) (unpublished data). These loci, together with $F v 4$ and $R m c f 2$, may therefore be representative of a larger set of interference genes found in virus infected mouse species. That such co-opted Env genes are effective as host antiviral factors is confirmed by the identification of comparable interfering env genes in chickens, sheep and cats [167-169].

\section{Fv1}

$F v 1$ is the oldest known retrovirus resistance gene [170] and represents a co-opted ERV sequence related to the gag gene of MuERV-L, a Class III ERV that is active in mice, but has no infectious virus counterparts $[171,172]$. The Fv1 sequence is found only in mice, and was acquired shortly after the origin of the Mus genus [173]. The laboratory mouse $F v 1$ has three well-characterized restriction alleles, and there are additional Fv1-like restrictions found in inbred strains and wild mouse species [173-176]. The three major laboratory mouse alleles, termed $F v 1^{n}, F v 1^{b}$, and $F v 1^{n r}$ produce characteristic patterns of resistance to N-, B-, and NR-tropic MLVs. Cells with the $F v 1$ null allele are nonrestrictive $[94,175]$, and NB-tropic viruses are not restricted by Fv1. Fv1 targets the virus capsid; the major determinant that distinguishes $\mathrm{N}$ - and B-tropic viruses is at CA position 110, but other target residues in this $\mathrm{CA}$ region have also been identified [176-180].

Because X-MLVs fail to infect cells of many laboratory mice, early studies used pseudotypes and recombinant viruses to suggest that X-MLVs are subject to $F v 1$ restriction [181,182]. Groom and colleagues [183] have more recently demonstrated that XMRV is unusual in 
that it is restricted in cells expressing either $F v 1^{n}$ or $F v 1^{b}$. Infection of X-MLV susceptible inbred strains suggests that XMRV is somewhat more sensitive to $F v 1^{n}$, and also indicates that various mouse X-MLVs can be restricted by $F v 1$ [52]. XMRV carries the $F v 1^{n}$ restricted residue at capsid target site 110 , but its sensitivity to both $F v 1^{n}$ and $F v 1^{b}$ and the presence of additional substitutions in its CA gene suggest that the $F v 1$ target is more complex than previously appreciated.

\section{Apobec3}

APOBEC3, like $F v 1$, is responsible for post-entry restriction of retroviral infection $[184,185]$. The mouse and human APOBEC3 genes are under strong positive selection suggesting an antiviral role in evolution [186,187]. There are 7 human APOBEC3 genes with differing antiviral activity against $\mathrm{HIV}-1$ as well as MLVs; the single mouse APOBEC3 gene blocks HIV-1 and various mouse retroviruses [188-190]. MAPOBEC3 can restrict EMLVs, and this gene maps to the site of the Friend virus restriction factor $R f v 3$ [191,192], a gene that influences the duration of viremia in virus-infected mice [193]. Pmvs but not Xmvs in the sequenced mouse genome show mutational patterns consistent with mAPOBEC3 silencing at the time of integration [25]. The sensitivity of infectious X/P-MLVs to APOBEC3 has not been determined, but XMRV is sensitive to inhibition by A3G, but is less sensitive or insensitive to A3A, A3B, $\mathrm{A} 3 \mathrm{C}, \mathrm{A} 3 \mathrm{~F}$ and $\mathrm{A} 3 \mathrm{H}$. XMRV is also more sensitive to mAPOBEC3 than is Moloney E-MLV [183,194].

The 2 laboratory mouse alleles of mAPOBEC3 vary in their restriction of Friend E-MLV replication and virusinduced disease, and differ in protein sequence, splicing pattern and expression levels [187,191,192,195]. The more antiviral allele of C57BL mice shows significantly higher levels of expression in mouse tissues [191,195], and this allele contains an Xmv LTR inserted into an intron [187]. This insertion introduces an intact LTR transcriptional enhancer, and all species and strains with this LTR show elevated mAPOBEC3 expression. This $X m v$, acquired in virus-infected mice [187], may thus represent another example of an ERV sequence that is co-opted by the virus-infected host for an antiviral function, like $F v 1$ and $R m c f$.

\section{Tetherin/BST2/CD317}

Tetherin, also termed BST2, CD317 or HM1.24, is an interferon-inducible host factor that blocks the release of enveloped viruses by tethering budding particles to the cell surface [196]. Tetherin can be antagonized by the VPU accessory protein of HIV-1 or by the Nef protein of SIV or by the envelope glycoproteins of various immunodeficiency viruses [197-201]. The effectiveness of these viral protein antagonists is species specific
[202], and these viral antagonists target different sites in tetherin [198]. Mouse E-MLV is subject to restriction by tetherin [196], and while the sensitivities of mouse X/PMLVs to this host factor are unknown, XMRV has now been shown to be sensitive to human, monkey and mouse tetherins [183]. XMRV, as a simple gammaretrovirus, lacks the accessory proteins of the immunodeficiency viruses that antagonize tetherin action, and its Env glycoprotein does not interfere with tetherin activity [183].

\section{Conclusions}

Multiple examples of xenotropism exist among the retroviruses. In addition to $\mathrm{X}-\mathrm{MLV}$, viruses that fail to infect cells of their apparent "home" species include the cat RD114-related viruses [203,204], GALV restriction in mice $[205,206]$, and restrictions of avian leukosis viruses [207]. However, a half century of work on the MLVs and the availability of multiple inbred strains and wild mouse species have provided a unique look at the natural history of this particular virus-host relationship. The picture that emerges indicates that these X/P-MLVs were acquired as endogenous elements by $M u s$ species with permissive receptors, and subsequent co-evolutionary modifications produced, among other adaptive phenotypes, "xenotropic" MLVs. The receptor mutations responsible for resistance to these X-MLVs were only recently acquired, and these restrictive receptors are only found among the inbred strains descended from early $20^{\text {th }}$ century fancy mouse colonies. It is now clear that the term "xenotropic" is somewhat of a misnomer for mouse viruses that actually infect cells of all Mus species and many common strains of laboratory mice, and that infect more non-Mus mammals than the socalled broad host range polytropic MLVs.

The interacting interfaces of host and pathogen are co-evolutionary battlegrounds, and the effects of the ratchet-like mutational process affecting these entities are particularly obvious for restriction factors like Xpr1 and $F v 1$. The battleground at the cell surface has produced at least 6 host range X/P-MLV variants that interact with different but overlapping sets of determinants on the XPR1 receptor. At the same time, other factors likely contribute to diversifying selection on the $\mathrm{X} / \mathrm{P}-\mathrm{MLV}$ viral Env glycoprotein, such as the Rmcf-type interfering ERVs and the inactivating LVIF serum factor. The resulting Envs not only vary in tropism, but these viruses have also evolved alternative mechanisms of transmission. Although germline PMV ERVs are effectively silenced, and the Env glycoproteins of infectious recombinant P-MLVs have narrow receptor requirements and reduced receptor binding efficiency, these multiple mechanisms ensure their transmission and also contribute to pathogenicity. 
MLV ERVs, as part of the host genome, are also shaped by evolutionary processes. ERV insertions introduce novel regulatory and protein coding sequences into the host genome. While most are silenced, some are coopted for cellular functions, and the most easily recognized of these domesticated ERVs are those that are linked to antiviral functions. Such ERVs include the oldest recognized restriction factor, $F v 1$, [170] as well as $\mathrm{X} /$ P-MLV ERV insertions that include the multiple Rmcflike interference genes, and regulatory elements like the mAPOBEC associated Xmv LTR.

The worldwide distribution of mice that carry MLVs and the broad host range of the X-MLVs suggest that we are only beginning to describe what may be common and widespread interspecies transmissions. The phenotypic diversity among the MLVs doubtless influences the likelihood of their transspecies transmission, and the invading viruses are then subject to additional co-evolutionary pressures. We do not know the evolutionary path taken by XMRV to humans, but multiple sequence and functional variations distinguish this virus from its MLV progenitors. The consequences of this transspecies MLV invasion are unclear, although XMRV pathophysiology is now being evaluated in other species, including primates [208] as well as in Mus species, like M. pahari, that are permissive for X-MLV and XMRV infection [209]. The fact that all mice carrying infectious X-MLVs have one of 3 restrictive receptors suggests that unchecked X-MLV infection is likely to be deleterious, and the recognition that many mice carry permissive receptors now makes it possible to describe the pathogenic consequences of exogenous X-MLV infection in their natural host. Further characterization of these viruses should further elucidate their evolutionary past and describe their pathogenic potential and the adaptations that favor co-existence of these infectious agents and their new human hosts.

\section{Acknowledgements}

This work was supported by the Intramural Research Program of the $\mathrm{NIH}_{\text {, }}$ NIAID.

\section{Competing interests}

The author declares that she has no competing interests.

Received: 19 October 2010 Accepted: 30 November 2010 Published: 30 November 2010

\section{References}

1. Gross L: "Spontaneous" leukemia developing in $\mathrm{C} 3 \mathrm{H}$ mice following inoculation in infancy, with AK-leukemic extracts, or AK-embrvos. Proc Soc Exp Biol Med 1951, 76:27-32.

2. Levy JA, Pincus T: Demonstration of biological activity of a murine leukemia virus of New Zealand Black mice. Science 1970, 170:326-327.

3. Oie HK, Russell EK, Dotson JH, Rhoads JM, Gazdar AF: Host range properties of murine xenotropic and ecotropic type-C viruses. J Natl Cancer Inst 1976, 56:423-426.

4. Levy JA: Host range of murine xenotropic virus: replication in avian cells. Nature 1975, 253:140-142.
5. Levy JA: Xenotropic viruses: murine leukemia viruses associated with $\mathrm{NIH}$ Swiss, NZB, and other mouse strains. Science 1973, 182:1151-1153.

6. Levy JA: Xenotropic type C viruses. Curr Top Microbiol Immunol 1978, 79:111-213.

7. Fischinger PJ, Nomura S, Bolognesi DP: A novel murine oncornavirus with dual eco- and xenotropic properties. Proc Natl Acad Sci USA 1975, 72:5150-5155.

8. Hartley JW, Wolford NK, Old LJ, Rowe WP: New class of murine leukemiavirus associated with development of spontaneous lymphomas. Proc Natl Acad Sci USA 1977, 74:789-792

9. Vogt M, Haggblom C, Swift S, Haas M: Specific sequences of the env gene determine the host range of two XC-negative viruses of the Rauscher virus complex. Virology 1986, 154:420-424.

10. Heard JM, Danos O: An amino-terminal fragment of the Friend murine leukemia virus envelope glycoprotein binds the ecotropic receptor. $J$ Virol 1991, 65:4026-4032.

11. Battini JL, Heard JM, Danos O: Receptor choice determinants in the envelope glycoproteins of amphotropic, xenotropic, and polytropic murine leukemia viruses. J Virol 1992, 66:1468-1475.

12. Albritton $L M$, Tseng $L$, Scadden $D$, Cunningham JM: A putative murine ecotropic retrovirus receptor gene encodes a multiple membranespanning protein and confers susceptibility to virus infection. Cell 1989, 57:659-666.

13. Tailor CS, Nouri A, Lee CG, Kozak C, Kabat D: Cloning and characterization of a cell surface receptor for xenotropic and polytropic murine leukemia viruses. Proc Natl Acad Sci USA 1999, 96:927-932.

14. Battini J-L, Rasko JEJ, Miller AD: A human cell-surface receptor for xenotropic and polytropic murine leukemia viruses: possible role in $\mathrm{G}$ protein-coupled signal transduction. Proc Natl Acad Sci USA 1999, 96:1385-1390

15. Yang Y-L, Guo L, Xu S, Holland CA, Kitamura T, Hunter K, Cunningham JM: Receptors for polytropic and xenotropic mouse leukaemia viruses encoded by a single gene at Rmc1. Nat Genet 1999, 21:216-219.

16. Waterston $\mathrm{RH}$, Lindblad-Toh K, Birney E, Rogers J, Abril JF, Agarwal $\mathrm{P}$ Agarwala R, Ainscough R, Alexandersson M, An P, et al: Initial sequencing and comparative analysis of the mouse genome. Nature 2002, 420:520-562.

17. Stocking C, Kozak C: Murine endogenous retroviruses. Cell Mol Life Sci 2008, 65:3383-3398.

18. Vogt V: Retroviral virions and genomes. In Retroviruses. Edited by: Coffin JA, Hughes SH, Varmus HE. Woodbury, NY: Cold Spring Harbor Laboratory Press; 1997:27-70.

19. Evans LH, Dresler S, Kabat D: Synthesis and glycosylation of polyprotein precursors to the internal core proteins of Friend murine leukemia virus. J Virol 1977, 24:865-874.

20. Edwards SA, Fan H: gag-Related polyproteins of Moloney murine leukemia virus: evidence for independent synthesis of glycosylated and unglycosylated forms. J Virol 1979, 30:551-563.

21. Prats AC, De Billy G, Wang P, Darlix JL: CUG initiation codon used for the synthesis of a cell surface antigen coded by the murine leukemia virus. J Mol Biol 1989, 205:363-372.

22. Kozak CA, Rowe WP: Genetic mapping of xenotropic murine leukemia virus-inducing loci in five mouse strains. J Exp Med 1980, 152:219-228.

23. Kozak CA, Rowe WP: Genetic mapping of ecotropic murine leukemia virus-inducing loci in six inbred strains. J Exp Med 1982, 155:524-534.

24. Frankel WN, Stoye JP, Taylor BA, Coffin JM: A linkage map of endogenous murine leukemia proviruses. Genetics 1990, 124:221-236.

25. Jern P, Stoye JP, Coffin JM: Role of APOBEC3 in genetic diversity among endogenous murine leukemia viruses. PLoS Genet 2007, 3:e183.

26. Jenkins NA, Copeland NG, Taylor BA, Lee BK: Organization, distribution, and stability of endogenous ecotropic murine leukemia virus DNA sequences in chromosomes of Mus musculus. J Virol 1982, 43:26-36.

27. Rowe WP, Pincus T: Quantitative studies of naturally occurring murine leukemia virus infection of AKR mice. J Exp Med 1972, 135:429-436.

28. Lowy DR, Rowe WP, Teich N, Hartley JW: Murine leukemia virus: highfrequency activation in vitro by 5-iododeoxyuridine and 5bromodeoxyuridine. Science 1971, 174:155-156.

29. Aaronson SA, Todaro GJ, Scolnick EM: Induction of murine C-type viruses from clonal lines of virus-free BALB/3T3 Cells. Science 1971, 174:157-159.

30. Buckler CE, Staal SP, Rowe WP, Martin MA: Variation in the number of copies and in the genomic organization of ecotropic murine leukemia virus proviral sequences in sublines of AKR mice. J Virol 1982, 43:629-640. 
31. Steffen DL, Taylor BA, Weinberg RA: Continuing germ line integration of AKV proviruses during the breeding of AKR mice and derivative recombinant inbred strains. J Virol 1982, 42:165-175.

32. Lock LF, Keshet E, Gilbert DJ, Jenkins NA, Copeland NG: Studies of the mechanism of spontaneous germline ecotropic provirus acquisition in mice. EMBO J 1988, 7:4169-4177.

33. O'Neill RR, Khan AS, Hoggan MD, Hartley JW, Martin MA, Repaske R. Specific hybridization probes demonstrate fewer xenotropic than mink cell focus-forming murine leukemia virus env-related sequences in DNAs from inbred laboratory mice. J Virol 1986, 58:359-366.

34. Stoye JP, Coffin JM: The four classes of endogenous murine leukemia virus: structural relationships and potential for recombination. I Virol 1987, 61:2659-2669.

35. Evans LH, Lavignon M, Taylor M, Alamgir AS: Antigenic subclasses of polytropic murine leukemia virus (MLV) isolates reflect three distinct groups of endogenous polytropic MLV-related sequences in NFS/N mice. J Virol 2003, 77:10327-10338.

36. Khan AS, Martin MA: Endogenous murine leukemia proviral long terminal repeats contain a unique 190-base-pair insert. Proc Natl Acad Sci USA 1983, 80:2699-2703.

37. Elder JH, Gautsch JW, Jensen FC, Lerner RA, Hartley JW, Rowe WP: Biochemical evidence that MCF murine leukemia viruses are envelope (env) gene recombinants. Proc Natl Acad Sci USA 1977, 74:4676-4680.

38. Khan AS, Rowe WP, Martin MA: Cloning of endogenous murine leukemia virus-related sequences from chromosomal DNA of BALB/C and AKR/J mice: identification of an env progenitor of AKR-247 mink cell focusforming proviral DNA. J Virol 1982, 44:625-636.

39. Chattopadhyay SK, Cloyd MW, Linemeyer DL, Lander MR, Rands E, Lowy DR: Cellular origin and role of mink cell focus-forming viruses in murine thymic lymphomas. Nature 1982, 295:25-31.

40. Rommelaere J, Faller DV, Hopkins N: Characterization and mapping of RNase T1-resistant oligonucleotides derived from the genomes of Akv and MCF murine leukemia viruses. Proc Natl Acad Sci USA 1978, 75:495-499.

41. Fischinger PJ, Blevins CS, Dunlop NM: Genomic masking of nondefective recombinant murine leukemia virus in Moloney virus stocks. Science 1978, 201:457-459

42. Lavignon M, Evans L: A multistep process of leukemogenesis in Moloney murine leukemia virus-infected mice that is modulated by retroviral pseudotyping and interference. J Virol 1996, 70:3852-3862.

43. Evans LH, Alamgir AS, Owens N, Weber N, Virtaneva K, Barbian K, Babar A, Malik F, Rosenke K: Mobilization of endogenous retroviruses in mice after infection with an exogenous retrovirus. J Virol 2009, 83:2429-2435.

44. Lavillette D, Ruggieri A, Russell SJ, Cosset FL: Activation of a cell entry pathway common to type $\mathrm{C}$ mammalian retroviruses by soluble envelope fragments. J Virol 2000, 74:295-304.

45. Wensel DL, Li W, Cunningham JM: A virus-virus interaction circumvents the virus receptor requirement for infection by pathogenic retroviruses. J Virol 2003, 77:3460-3469.

46. Frankel WN, Stoye JP, Taylor BA, Coffin JM: Genetic analysis of endogenous xenotropic murine leukemia viruses: association with two common mouse mutations and the viral restriction locus Fv-1. J Virol 1989, 63:1763-1774

47. Morse HC III, Kozak CA, Yetter RA, Hartley JW: Unique features of retrovirus expression in F/St mice. J Virol 1982, 43:1-7.

48. East J, Tilly RJ, Tuffrey M, Harvey JJ: The early appearance and subsequent distribution of murine leukaemia virus in NZB embryos. Int I Cancer 1978, 22:495-502.

49. Greenberger JS, Phillips SM, Stephenson JR, Aaronson SA: Induction of mouse type-C RNA virus by lipopolysaccharide. J Immunol 1975, 115:317-320

50. Sherr CJ, Lieber MM, Todaro GJ: Mixed splenocyte cultures and graft versus host reactions selectively induce an S-tropic murine type $\mathrm{C}$ virus. Cell 1974, 1:55-58.

51. Kozak C, Rowe WP: Genetic mapping of xenotropic leukemia virusinducing loci in two mouse strains. Science 1978, 199:1448-1449.

52. Baliji SLQ, Kozak CA: Common inbred strains of the laboratory mouse that are susceptible to infection by mouse xenotropic gammaretroviruses and the human derived XMRV. J Virol 2010, 84:12841-12849.

53. Hoggan MD, O'Neill RR, Kozak CA: Nonecotropic murine leukemia viruses in BALB/C and NFS/N mice: characterization of the BALB/C BXv-1 provirus and the single NFS endogenous xenotrope. J Virol 1986, 60:980-986.
54. Yetter RA, Hartley JW, Morse HC III: $\mathrm{H}$-2-linked regulation of xenotropic murine leukemia virus expression. Proc Natl Acad Sci USA 1983, 80:505-509.

55. Datta SK, Schwartz RS: Mendelian segregation of loci controlling xenotropic virus production in NZB crosses. Virology 1977, 83:449-452.

56. Elder JH, Gautsch JW, Jensen FC, Lerner RA, Chused TM, Morse HC, Hartley JW, Rowe WP: Differential expression of two distinct xenotropic viruses in NZB mice. Clin Immunol Immunopathol 1980, 15:493-501.

57. Kozak CA, Hartley JW, Morse HC: Laboratory and wild-derived mice with multiple loci for production of xenotropic murine leukemia virus. J Virol 1984, 51:77-80

58. Morse HC III, Chused TM, Boehm-Truitt M, Mathieson BJ, Sharrow SO, Hartley JW: XenCSA: cell surface antigens related to the major glycoproteins (gp70) of xenotropic murine leukemia viruses. J Immunol 1979, 122:443-454.

59. Obata $Y$, Ikeda $H$, Stockert E, Boyse EA: Relation of $G_{1 X}$ antigen of thymocytes to envelope glycoprotein of murine leukemia virus. J Exp Med 1975, 141:188-197.

60. Old $L$, Stockert E: Immunogenetics of cell surface antigens of mouse leukemia. Annu Rev Genet 1977, 11:127-160.

61. Morse HC, Taylor BA, Kozak CA, Chused TM, Sharrow SO, Hartley JW, Stockert E: Expression on normal lymphocytes of two cell surface antigens, XenCSA and $\mathrm{G}_{\mathrm{I} \text {, }}$, related to the major glycoproteins (gp70) of murine leukemia viruses. J Immunol 1982, 128:2111-2115.

62. Hartley JW, Evans LH, Green KY, Naghashfar Z, Macias AR, Zerfas PM Ward JM: Expression of infectious murine leukemia viruses by RAW264.7 cells, a potential complication for studies with a widely used mouse macrophage cell line. Retrovirology 2008, 5:1.

63. Lundrigan BL, Jansa SA, Tucker PK: Phylogenetic relationships in the genus Mus, based on paternally, maternally, and biparentally inherited characters. Systematic Biology 2002, 51:410-431.

64. Veyrunes F, Dobigny G, Yang F, O'Brien PC, Catalan J, Robinson TJ, BrittonDavidian J: Phylogenomics of the genus Mus (Rodentia; Muridae): extensive genome repatterning is not restricted to the house mouse. Proc Biol Sci 2006, 273:2925-2934.

65. Yonekawa H, Moriwaki K, Gotoh O, Miyashita N, Matsushima Y, Shi L, Cho W, Zhen X, Tagashira Y: Hybrid origin of Japanese mice "Mus musculus molossinus": evidence from restriction analysis of mitochondrial DNA. Mol Biol Evol 1988, 5:63-78.

66. Boursot P, Auffray JC, Britton-Davidian J, Bonhomme F: The Evolution of House Mice. Annual Review of Ecology and Systematics 1993, 24:119-152.

67. Geraldes A, Basset P, Gibson B, Smith KL, Harr B, Yu HT, Bulatova N, Ziv Y, Nachman MW: Inferring the history of speciation in house mice from autosomal, X-linked, Y-linked and mitochondrial genes. Mol Ecol 2008, 17:5349-5363.

68. Sage R, Atchley WR, Capanna E: House mice as models in systematic biology. Syst Biol 1993, 42:523-561.

69. Yang H, Bell TA, Churchill GA, Pardo-Manuel de Villena F: On the subspecific origin of the laboratory mouse. Nat Genet 2007, 39:1100-1107.

70. Morse HCl: Introduction. In Origins of inbred mice. Edited by: HCM III. New York, NY: Academic Press; 1978:1-31.

71. Kozak CA, O'Neill RR: Diverse wild mouse origins of xenotropic, mink cell focus-forming, and two types of ecotropic proviral genes. J Virol 1987 61:3082-3088

72. Tomonaga $\mathrm{K}$, Coffin JM: Structure and distribution of endogenous nonecotropic murine leukemia viruses in wild mice. J Virol 1998, 72:8289-8300.

73. Tomonaga K, Coffin JM: Structures of endogenous nonecotropic murine leukemia virus (MLV) long terminal repeats in wild mice: implication for evolution of MLVs. J Virol 1999, 73:4327-4340.

74. Inaguma Y, Miyashita N, Moriwaki K, Huai WC, Jin ML, He XQ, Ikeda H: Acquisition of two endogenous ecotropic murine leukemia viruses in distinct Asian wild mouse populations. J Virol 1991, 65:1796-1802.

75. Lieber $\mathrm{M}$, Sherr $\mathrm{C}$, Potter M, Todaro G: Isolation of type-C viruses from the Asian feral mouse Mus musculus molossinus. Int I Cancer 1975, 15:211-220.

76. Chattopadhyay SK, Lander MR, Gupta S, Rands E, Lowy DR: Origin of mink cytopathic focus-forming (MCF) viruses: comparison with ecotropic and xenotropic murine leukemia virus genomes. Virology 1981, 113:465-483.

77. Cloyd MW, Thompson MM, Hartley JW: Host range of mink cell focusinducing viruses. Virology 1985, 140:239-248. 
78. Yan Y, Knoper RC, Kozak CA: Wild mouse variants of envelope genes of xenotropic/polytropic mouse gammaretroviruses and their XPR1 receptors elucidate receptor determinants of virus entry. J Virol 2007 81:10550-10557.

79. Yan Y, Liu Q, Kozak CA: Six host range variants of the xenotropic/ polytropic gammaretroviruses define determinants for entry in the XPR1 cell surface receptor. Retrovirology 2009, 6:87.

80. Lathrop AEC, Loeb L: Further investigations on the origin of tumors in mice. J Exp Med 1918, 28:475-500.

81. Schwarz E: Origin of the Japanese waltzing mouse. Science 1942, 95:46.

82. Jung YT, Wu T, Kozak CA: Characterization of recombinant nonecotropic murine leukemia viruses from the wild mouse species Mus spretus. J Virol 2003, 77:12773-12781.

83. O'Neill RR, Hartley JW, Repaske R, Kozak CA: Amphotropic proviral envelope sequences are absent from the Mus germ line. J Virol 1987, 61:2225-2231.

84. Voytek P, Kozak CA: Nucleotide sequence and mode of transmission of the wild mouse ecotropic virus, HoMuLV. Virology 1989, 173:58-67.

85. Alamgir AS, Owens N, Lavignon M, Malik F, Evans LH: Precise identification of endogenous proviruses of NFS/N mice participating in recombination with Moloney ecotropic murine leukemia virus (MuLV) to generate polytropic MuLVs. J Virol 2005, 79:4664-4671.

86. Jahid S, Bundy LM, Granger SW, Fan H: Chimeras between SRS and Moloney murine leukemia viruses reveal novel determinants in disease specificity and MCF recombinant formation. Virology 2006, 351:7-17.

87. Pedersen FS, Crowther RL, Tenney DY, Reimold AM, Haseltine WA: Novel leukaemogenic retroviruses isolated from cell line derived from spontaneous AKR tumour. Nature 1981, 292:167-170.

88. Famulari NG, Koehne CF, O'Donnell PV: Leukemogenesis by Gross passage A murine leukemia virus: expression of viruses with recombinant env genes in transformed cells. Proc Natl Acad Sci USA 1982, 79:3872-3876.

89. Cloyd MW, Chattopadhyay SK: A new class of retrovirus present in many murine leukemia systems. Virology 1986, 151:31-40.

90. Bahrami S, Duch M, Pedersen FS: Change of tropism of SL3-2 murine leukemia virus, using random mutational libraries. J Virol 2004, 78:9343-9351.

91. Chattopadhyay SK, Oliff Al, Linemeyer DL, Lander MR, Lowy DR: Genomes of murine leukemia viruses isolated from wild mice. J Virol 1981, 39:777-791.

92. Kozak CA: Genetic mapping of a mouse chromosomal locus required for mink cell focus-forming virus replication. J Virol 1983, 48:300-303.

93. Hartley JW, Rowe WP: Clonal cell lines from a feral mouse embryo which lack host-range restrictions for murine leukemia viruses. Virology 1975, 65:128-134.

94. Lander MR, Chattopadhyay SK: A Mus dunni cell line that lacks sequences closely related to endogenous murine leukemia viruses and can be infected by ecotropic, amphotropic, xenotropic, and mink cell focusforming viruses. J Virol 1984, 52:695-698.

95. Kozak CA: Susceptibility of wild mouse cells to exogenous infection with xenotropic leukemia viruses: control by a single dominant locus on chromosome 1. J Virol 1985, 55:690-695.

96. Lyu MS, Kozak CA: Genetic basis for resistance to polytropic murine leukemia viruses in the wild mouse species Mus castaneus. J Virol 1996, 70:830-833.

97. Chesebro B, Wehrly K: Different murine cell lines manifest unique patterns of interference to superinfection by murine leukemia viruses. Virology 1985, 141:119-129.

98. Tailor CS, Lavillette D, Marin M, Kabat D: Cell surface receptors for gammaretroviruses. Curr Top Microbiol Immunol 2003, 281:29-106.

99. Overbaugh J, Miller AD, Eiden MV: Receptors and entry cofactors for retroviruses include single and multiple transmembrane-spanning proteins as well as newly described glycophosphatidylinositol-anchored and secreted proteins. Microbiol Mol Biol Rev 2001, 65:371-389, table of contents.

100. Sharma P, Patntirapong S, Hann S, Hauschka PV: RANKL-RANK signaling regulates expression of xenotropic and polytropic virus receptor (XPR1) in osteoclasts. Biochem Biophys Res Commun 2010, 399:129-132.

101. Yan Y, Liu Q, Wollenberg K, Martin C, Buckler-White A, Kozak CA: Evolution of functional and sequence variants of the mammalian XPR1 receptor for mouse xenotropic gammaretroviruses and the human-derived XMRV. J Virol 2010, 84:11970-11980.
102. Marin M, Tailor CS, Nouri A, Kozak SL, Kabat D: Polymorphisms of the cell surface receptor control mouse susceptibilities to xenotropic and polytropic leukemia viruses. J Virol 1999, 73:9362-9368.

103. Van Hoeven NS, Miller AD: Use of different but overlapping determinants in a retrovirus receptor accounts for non-reciprocal interference between xenotropic and polytropic murine leukemia viruses. Retrovirology 2005, 2:76.

104. Brown JK, Fung C, Tailor CS: Comprehensive mapping of receptorfunctioning domains in feline leukemia virus subgroup $C$ receptor FLVCR1. J Virol 2006, 80:1742-1751.

105. Farrell KB, Russ $J$, Murthy RK, Eiden MV: Reassessing the role of region $A$ in Pit1-mediated viral entry. J Virol 2002, 76:7683-7693.

106. Manel N, Battini JL, Sitbon M: Human T cell leukemia virus envelope binding and virus entry are mediated by distinct domains of the glucose transporter GLUT1. J Biol Chem 2005, 280:29025-29029.

107. Avner P, Amar L, Dandolo L, Guenet JL: Genetic analysis of the mouse using interspecific crosses. Trends Genet 1988, 4:18-23.

108. Beck JA, Lloyd S, Hafezparast M, Lennon-Pierce M, Eppig JT, Festing MFW Fisher EMC: Genealogies of mouse inbred strains. Nat Genet 2000, 24:23-25.

109. Gardner MB, Chiri A, Dougherty MF, Casagrande J, Estes JD: Congenital transmission of murine leukemia virus from wild mice prone to the development of lymphoma and paralysis. J Natl Cancer Inst 1979, 62:63-70.

110. Portis $J$, McAtee FJ, Hayes SF: Horizontal transmission of murine retroviruses. J Virol 1987, 61:1037-1044.

111. Marshall J: Taxonomy. In The mouse in biomedical research. Volume 1. Edited by: Foster HL SJ, Fox JG. New York, NY: Academic Press; 1981:17-26.

112. Weber WJ: Diseases transmitted by rats and mice Fresno, CA: Thomas Publishers; 1982

113. Martin J, Herniou E, Cook J, O'Neill RW, Tristem M: Interclass transmission and phyletic host tracking in murine leukemia virus-related retroviruses. J Virol 1999, 73:2442-2449.

114. Urisman A, Molinaro RJ, Fischer N, Plummer SJ, Casey G, Klein EA, Malathi K, Magi-Galluzzi C, Tubbs RR, Ganem D, et al: Identification of a novel gammaretrovirus in prostate tumors of patients homozygous for R462Q RNASEL variant. PLoS Pathog 2006, 2:e25.

115. Dong B, Kim S, Hong S, Das Gupta J, Malathi K, Klein EA, Ganem D, DeRisi JL, Chow SA, Silverman RH: An infectious retrovirus susceptible to an IFN antiviral pathway from human prostate tumors. Proc Natl Acad Sci USA 2007, 104:1655-1660.

116. Schlaberg R, Choe DJ, Brown KR, Thaker HM, Singh IR: XMRV is present in malignant prostatic epithelium and is associated with prostate cancer, especially high-grade tumors. Proc Natl Acad Sci USA 2009, 106:16351-16356.

117. Lombardi VC, Ruscetti FW, Das Gupta J, Pfost MA, Hagen KS, Peterson DL, Ruscetti SK, Bagni RK, Petrow-Sadowski C, Gold B, et al: Detection of an infectious retrovirus, XMRV, in blood cells of patients with chronic fatigue syndrome. Science 2009, 326:585-589.

118. Knouf EC, Metzger MJ, Mitchell PS, Arroyo JD, Chevillet JR, Tewari M, Miller AD: Multiple integrated copies and high-level production of the human retrovirus XMRV (xenotropic murine leukemia virus-related virus) from 22Rv1 prostate carcinoma cells. J Virol 2009, 83:7353-7356.

119. Lo SC, Pripuzova N, Li B, Komaroff AL, Hung GC, Wang R, Alter HJ: Detection of MLV-related virus gene sequences in blood of patients with chronic fatigue syndrome and healthy blood donors. Proc Natl Acad Sci USA 2010, 107:15874-15879.

120. Raisch KP, Pizzato M, Sun HY, Takeuchi Y, Cashdollar LW, Grossberg SE: Molecular cloning, complete sequence, and biological characterization of a xenotropic murine leukemia virus constitutively released from the human B-lymphoblastoid cell line DG-75. Virology 2003, 308:83-91.

121. Courgnaud V, Battini JL, Sitbon M, Mason AL: Mouse retroviruses and chronic fatigue syndrome: Does $\times$ (or P) mark the spot? Proc Natl Acad Sci USA 2010, 107:15666-15667.

122. Silverman $\mathrm{RH}$, Nguyen $\mathrm{C}$, Weight $\mathrm{CJ}$, Klein EA: The human retrovirus XMRV in prostate cancer and chronic fatigue syndrome. Nat Rev Urol 2010, 7:392-402.

123. Curado MPEB, Shin HR, Storm H, Ferlay J, Heanue M, Boyle P: Cancer incidence in five continents, vol. IX. IARC scientific publication no 160 Lyon, France: IARC; 2007. 
124. Wu T, Yan Y, Kozak CA: Rmcf2, a xenotropic provirus in the Asian mouse species Mus castaneus, blocks infection by polytropic mouse gammaretroviruses. J Virol 2005, 79:9677-9684

125. Nitta T, Kuznetsov $Y$, McPherson A, Fan $H$ : Murine leukemia virus glycosylated Gag ( $\mathrm{gPr} 80^{g a g}$ ) facilitates interferon-sensitive virus release through lipid rafts. Proc Natl Acad Sci USA 2010, 107:1190-1195.

126. Kolokithas A, Rosenke K, Malik F, Hendrick D, Swanson L, Santiago ML, Portis JL, Hasenkrug KJ, Evans LH: The glycosylated Gag protein of a murine leukemia virus inhibits the antiretroviral function of APOBEC3. $J$ Virol 2010, 84:10933-10936.

127. Stieler K, Schulz C, Lavanya M, Aepfelbacher M, Stocking C, Fischer N: Host range and cellular tropism of the human exogenous gammaretrovirus XMRV. Virology 2010, 399:23-30.

128. Dong B, Silverman $\mathrm{RH}$ : Androgen stimulates transcription and replication of xenotropic murine leukemia virus-related virus. J Virol 2010, 84:1648-1651.

129. Rodriguez JJ, Goff SP: Xenotropic murine leukemia virus-related virus establishes an efficient spreading infection and exhibits enhanced transcriptional activity in prostate carcinoma cells. J Virol 2010, 84:2556-2562.

130. Rosenberg N, Jolicoeur P: Retroviral Pathogenesis. In Retroviruses. Edited by: Coffin JM, Hughes SH, Varmus HE. Woodbury, NY: Cold Spring Harbor Laboratory Press; 1997:475-586.

131. Suzuki $T$, Shen $H$, Akagi K, Morse HC, Malley JD, Naiman DQ, Jenkins NA, Copeland NG: New genes involved in cancer identified by retroviral tagging. Nat Genet 2002, 32:166-174.

132. Kim S, Kim N, Dong B, Boren D, Lee SA, Das Gupta J, Gaughan C, Klein EA Lee $\mathrm{C}$, Silverman $\mathrm{RH}$, Chow SA: Integration site preference of xenotropic murine leukemia virus-related virus, a new human retrovirus associated with prostate cancer. J Virol 2008, 82:9964-9977.

133. Fan H: Leukemogenesis by Moloney murine leukemia virus: a multistep process. Trends Microbiol 1997, 5:74-82.

134. Stoye JP, Moroni C, Coffin JM: Virological events leading to spontaneous AKR thymomas. J Virol 1991, 65:1273-1285.

135. Herr W, Gilbert W: Somatically acquired recombinant murine leukemia proviruses in thymic leukemias of AKR/J mice. J Virol 1983, 46:70-82.

136. Cloyd MW, Hartley JW, Rowe WP: Lymphomagenicity of recombinant mink cell focus-inducing murine leukemia viruses. J Exp Med 1980, 151:542-552.

137. Buller RS, Sitbon M, Portis JL: The endogenous mink cell focus-forming (MCF) gp70 linked to the Rmcf gene restricts MCF virus replication in vivo and provides partial resistance to erythroleukemia induced by Friend murine leukemia virus. J Exp Med 1988, 167:1535-1546.

138. Brightman BK, Rein A, Trepp DJ, Fan H: An enhancer variant of Moloney murine leukemia virus defective in leukemogenesis does not generate detectable mink cell focus-inducing virus in vivo. Proc Natl Acad Sci USA 1991, 88:2264-2268.

139. Quint W, Boelens W, van Wezenbeek P, Robanus Maandag E, Berns A: Generation of AKR mink cell focus-forming virus: nucleotide sequence of the $3^{\prime}$ end of a somatically acquired AKR-MCF. Virology 1984, 136:425-434.

140. Li JP, D'Andrea AD, Lodish HF, Baltimore D: Activation of cell growth by binding of Friend spleen focus-forming virus gp55 glycoprotein to the erythropoietin receptor. Nature 1990, 343:762-764

141. Nishigaki K, Hanson C, Jelacic T, Thompson D, Ruscetti S: Friend spleen focus-forming virus transforms rodent fibroblasts in cooperation with a short form of the receptor tyrosine kinase Stk. Proc Natl Acad Sci USA 2005, 102:15488-15493.

142. Moreau-Gachelin F: Multi-stage Friend murine erythroleukemia: molecular insights into oncogenic cooperation. Retrovirology 2008, 5:99.

143. Tumas KM, Poszgay JM, Avidan N, Ksiazek SJ, Overmoyer B, Blank KJ, Prystowsky MB: Loss of antigenic epitopes as the result of env gene recombination in retrovirus-induced leukemia in immunocompetent mice. Virology 1993, 192:587-595.

144. Mangeney M, Pothlichet J, Renard M, Ducos B, Heidmann T: Endogenous retrovirus expression is required for murine melanoma tumor growth in vivo. Cancer Res 2005, 65:2588-2591.

145. Pothlichet J, Heidmann T, Mangeney M: A recombinant endogenous retrovirus amplified in a mouse neuroblastoma is involved in tumor growth in vivo. Int J Cancer 2006, 119:815-822.
146. Herr W, Gilbert W: Free and integrated recombinant murine leukemia virus DNAs appear in preleukemic thymuses of AKR/J mice. J Virol 1984, 50:155-162.

147. Temin HM: Mechanisms of cell killing/cytopathic effects by nonhuman retroviruses. Rev Infect Dis 1988, 10:399-405.

148. Cheng-Mayer C, Seto D, Tateno M, Levy JA: Biologic features of HIV-1 that correlate with virulence in the host. Science 1988, 240:80-82

149. Yoshimura FK, Wang T, Yu F, Kim HR, Turner JR: Mink cell focus-forming murine leukemia virus infection induces apoptosis of thymic lymphocytes. J Virol 2000, 74:8119-8126.

150. Nanua S, Yoshimura FK: Mink epithelial cell killing by pathogenic murine leukemia viruses involves endoplasmic reticulum stress. J Virol 2004 78:12071-12074.

151. Eiden MV, Farrell K, Wilson CA: Glycosylation-dependent inactivation of the ecotropic murine leukemia-virus receptor. J Virol 1994, 68:626-631.

152. Yan $Y$, Jung $Y T, W u T$, Kozak CA: Role of receptor polymorphism and glycosylation in syncytium induction and host range variation of ecotropic mouse gammaretroviruses. Retrovirology 2008, 5:2.

153. Miller DG, Miller AD: Tunicamycin treatment of $\mathrm{CHO}$ cells abrogates multiple blocks to retrovirus infection, one of which is due to a secreted inhibitor. J Virol 1992, 66:78-84

154. Levy JA, Ihle JN, Oleszko O, Barnes RD: Virus-specific neutralization by a soluble non-immunoglobulin factor found naturally in normal mouse sera. Proc Natl Acad Sci USA 1975, 72:5071-5075.

155. Leong JC, Kane JP, Oleszko O, Levy JA: Antigen-specific nonimmunoglobulin factor that neutralizes xenotropic virus is associated with mouse serum lipoproteins. Proc Natl Acad Sci USA 1977, 74:276-280.

156. Fischinger PJ, Ihle JN, Bolognesi DP, Schafer W: Inactivation of murine xenotropic oncornavirus by normal mouse sera is not immunoglobulinmediated. Virology 1976, 71:346-351.

157. Kane JP, Hardman DA, Dimpfl JC, Levy JA: Apolipoprotein is responsible for neutralization of xenotropic type $C$ virus by mouse serum. Proc Natl Acad Sci USA 1979, 76:5957-5961.

158. Welsh RM, Cooper NR, Jensen FC, Oldstone MB: Human serum lyses RNA tumour viruses. Nature 1975, 257:612-614.

159. Takeuchi Y, Porter CD, Strahan KM, Preece AF, Gustafsson K, Cosset FL, Weiss RA, Collins MK: Sensitization of cells and retroviruses to human serum by (a1-3) galactosyltransferase. Nature 1996, 379:85-88.

160. Wu TY, Lee CG, Buckler-White A, Kozak CA: Genetic control of a mouse serum lipoprotein factor that inactivates murine leukemia viruses: Evaluation of apolipoprotein F as a candidate. J Virol 2002, 76:2279-2286

161. Ikeda H, Laigret F, Martin MA, Repaske R: Characterization of a molecularly cloned retroviral sequence associated with Fv-4 resistance. J Virol 1985, 55:768-777.

162. Ruscetti S, Davis L, Feild J, Oliff A: Friend murine leukemia virus-induced leukemia is associated with the formation of mink cell focus-inducing viruses and is blocked in mice expressing endogenous mink cell focusinducing xenotropic viral envelope genes. J Exp Med 1981, 154:907-920.

163. Bassin RH, Ruscetti S, Ali I, Haapala DK, Rein A: Normal DBA/2 mouse cells synthesize a glycoprotein which interferes with MCF virus-infection. Virology 1982, 123:139-151.

164. Hartley JW, Yetter RA, Morse HC: A mouse gene on chromosome 5 that restricts infectivity of mink cell focus-forming recombinant murine leukemia viruses. J Exp Med 1983, 158:16-24.

165. Jung YT, Lyu MS, Buckler-White A, Kozak CA: Characterization of a polytropic murine leukemia virus proviral sequence associated with the virus resistance gene Rmcf of DBA/2 mice. J Virol 2002, 76:8218-8224.

166. Taylor GM, Gao Y, Sanders DA: Fv-4: identification of the defect in Env and the mechanism of resistance to ecotropic murine leukemia virus J Virol 2001, 75:11244-11248.

167. Robinson HL, Astrin SM, Senior AM, Salazar FH: Host susceptibility to endogenous viruses: defective, glycoprotein-expressing proviruses interfere with infections. J Virol 1981, 40:745-751.

168. Spencer TE, Mura M, Gray CA, Griebel PJ, Palmarini M: Receptor usage and fetal expression of ovine endogenous betaretroviruses: implications for coevolution of endogenous and exogenous retroviruses. J Virol 2003, 77:749-753. 
169. McDougall AS, Terry A, Tzavaras T, Cheney C, Rojko J, Neil JC: Defective endogenous proviruses are expressed in feline lymphoid cells: evidence for a role in natural resistance to subgroup B feline leukemia viruses. J Virol 1994, 68:2151-2160.

170. Lilly F: Susceptibility to two strains of Friend leukemia virus in mice. Science 1967, 155:461-462.

171. Best S, LeTissier P, Towers G, Stoye JP: Positional cloning of the mouse retrovirus restriction gene Fv1. Nature 1996, 382:826-829.

172. Benit L, DeParseval N, Casella JF, Callebaut I, Cordonnier A, Heidmann T: Cloning of a new murine endogenous retrovirus, MuERV-L, with strong similarity to the human HERV-L element and with a gag coding sequence closely related to the Fv1 restriction gene. J Virol 1997, 71:5652-5657.

173. Yan Y, Buckler-White A, Wollenberg K, Kozak CA: Origin, antiviral function and evidence for positive selection of the gammaretrovirus restriction gene Fv1 in the genus Mus. Proc Natl Acad Sci USA 2009, 106:3259-3263.

174. Hartley JW, Rowe WP, Huebner RJ: Host-range restrictions of murine leukemia viruses in mouse embryo cell cultures. J Virol 1970, 5:221-225.

175. Kozak CA: Analysis of wild-derived mice for $F v-1$ and $F v-2$ murine leukemia virus restriction loci: a novel wild mouse $F v-1$ allele responsible for lack of host range restriction. J Virol 1985, 55:281-285.

176. Kozak CA, Chakraborti A: Single amino acid changes in the murine leukemia virus capsid protein gene define the target of Fv1 resistance. Virology 1996, 225:300-305.

177. Jung YT, Kozak CA: A single amino acid change in the murine leukemia virus capsid gene responsible for the $F v 1^{n r}$ phenotype. J Virol 2000, 74:5385-5387.

178. Stevens A, Bock M, Ellis S, LeTissier P, Bishop KN, Yap MW, Taylor W, Stoye JP: Retroviral capsid determinants of Fv1 NB and NR tropism. J Virol 2004, 78:9592-9598.

179. Lassaux A, Sitbon M, Battini $J$ : Residues in the murine leukemia virus capsid that differentially govern resistance to mouse Fv1 and human Ref1 restrictions. J Virol 2005, 79:6560-6564.

180. Ulm JW, Perron M, Sodroski J, R CM: Complex determinants within the Moloney murine leukemia virus capsid modulate susceptibility of the virus to Fv1 and Ref1-mediated restriction. Virology 2007, 363:245-255.

181. Sakai K, Narita H, Adachi A, Tsuruta S, Yorifuji T, Ishimoto A: Fv-1 determinants in xenotropic murine leukemia viruses studied with biological assay systems: Isolation of xenotropic virus with $\mathrm{N}$-tropic $\mathrm{Fv}$ - 1 activity in the cryptic form. J Virol 1982, 42:331-336.

182. Gautsch JW, Elder JH, Jensen FC, Lerner RA: In vitro construction of a Btropic virus by recombination: B-tropism is a cryptic phenotype of xenotropic murine retroviruses. Proc Natl Acad Sci USA 1980, 77:2989-2993.

183. Groom HCT, Yap MW, Galão RP, Neil SJD, Bishop KN: Susceptibility of xenotropic murine leukemia virus-related virus (XMRV) to retroviral restriction factors. Proc Natl Acad Sci USA 2010, 107:5166-5171.

184. Harris RS, Bishop KN, Sheehy AM, Craig HM, Petersen-Mahrt SK, Watt IN, Neuberger MS, Malim MH: DNA deamination mediates innate immunity to retroviral infection. Cell 2003, 113:803-809.

185. Goila-Gaur R, Strebel K: HIV-1 Vif, APOBEC, and intrinsic immunity. Retrovirology 2008, 5:51.

186. Sawyer SL, Emerman M, Malik HS: Ancient adaptive evolution of the primate antiviral DNA-editing enzyme APOBEC3G. PLOS Biol 2004, 2:E275

187. Sanville B, Dolan MA, Wollenberg K, Yan Y, Martin C, Yeung ML, Strebel K, Buckler-White A, Kozak CA: Adaptive evolution of Mus Apobec3 includes retroviral insertion and positive selection at two clusters of residues flanking the substrate groove. PLOS Pathog 2010, 6:e1000974.

188. Okeoma CM, Lovsin N, Peterlin BM, Ross SR: APOBEC3 inhibits mouse mammary tumour virus replication in vivo. Nature 2007, 445:927-930.

189. Esnault C, Heidmann O, Delebecque F, Dewannieux M, Ribet D, Hance AJ, Heidmann T, Schwartz O: APOBEC3G cytidine deaminase inhibits retrotransposition of endogenous retroviruses. Nature 2005, 433:430-433.

190. Mikl MC, Watt IN, Lu M, Reik W, Davies SL, Neuberger MS, Rada C: Mice deficient in APOBEC2 and APOBEC3. Mol Cell Biol 2005, 25:7270-7277.

191. Takeda E, Tsuji-Kawahara S, Sakamoto M, Langlois MA, Neuberger MS, Rada C, Miyazawa M: Mouse APOBEC3 restricts Friend leukemia virus infection and pathogenesis in vivo. J Virol 2008, 82:10998-11008.

192. Santiago ML, Montano M, Benitez R, Messer RJ, Yonemoto W, Chesebro B, Hasenkrug KJ, Greene WC: Apobec3 encodes Rfv3, a gene influencing neutralizing antibody control of retrovirus infection. Science 2008, 321:1343-1346.
193. Chesebro B, Wehrly K: Identification of a non- $H-2$ gene ( $R f v-3)$ influencing recovery from viremia and leukemia induced by Friend virus complex. Proc Natl Acad Sci USA 1979, 76:425-429.

194. Stieler K, Fischer N: Apobec $3 G$ efficiently reduces infectivity of the human exogenous gammaretrovirus XMRV. PLoS One 2010, 5:e11738.

195. Okeoma CM, Petersen J, Ross SR: Expression of murine APOBEC3 alleles in different mouse strains and their effect on mouse mammary tumor virus infection. J Virol 2009, 83:3029-3038.

196. Neil SJD, Zang T, Bieniasz PD: Tetherin inhibits retrovirus release and is antagonized by HIV-1 Vpu. Nature 2008, 451:425-U421.

197. Van Damme N, Goff D, Katsura C, Jorgenson RL, Mitchell R, Johnson MC Stephens EB, Guatelli J: The interferon-induced protein BST-2 restricts HIV-1 release and is downregulated from the cell surface by the viral Vpu protein. Cell Host Microbe 2008, 3:245-252.

198. Jia B, Serra-Moreno R, Neidermyer W, Rahmberg A, Mackey J, Fofana IB, Johnson WE, Westmoreland S, Evans DT: Species-specific activity of SIV Nef and HIV-1 Vpu in overcoming restriction by tetherin/BST2. PLOS Pathog 2009, 5:e1000429.

199. Zhang F, Wilson SJ, Landford WC, Virgen B, Gregory D, Johnson MC, Munch J, Kirchhoff F, Bieniasz PD, Hatziioannou T: Nef proteins from simian immunodeficiency viruses are tetherin antagonists. Cell Host Microbe 2009, 6:54-67.

200. Gupta RK, Mlcochova P, Pelchen-Matthews A, Petit SJ, Mattiuzzo G, Pillay D, Takeuchi Y, Marsh M, Towers GJ: Simian immunodeficiency virus envelope glycoprotein counteracts tetherin/BST-2/CD317 by intracellular sequestration. Proc Natl Acad Sci USA 2009, 106:20889-20894

201. Le Tortorec A, Neil SJ: Antagonism to and intracellular sequestration of human tetherin by the human immunodeficiency virus type 2 envelope glycoprotein. J Virol 2009, 83:11966-11978.

202. McNatt MW, Zang T, Hatziioannou T, Bartlett M, Fofana IB, Johnson WE, Neil SJ, Bieniasz PD: Species-specific activity of HIV-1 Vpu and positive selection of tetherin transmembrane domain variants. PLOS Pathog 2009, 5:e1000300.

203. Livingston DM, Todaro GJ: Endogenous type $C$ virus from a cat cell clone with properties distinct from previously described feline type $C$ virus Virology 1973, 53:142-151.

204. Sarma PS, Tseng J, Lee YK, Gilden RV: Virus similar to RD114 virus in cat cells. Nat New Biol 1973, 244:56-59.

205. Todaro GJ, Lieber MM, Benveniste RE, Sherr CJ: Infectious primate type C viruses: Three isolates belonging to a new subgroup from the brains of normal gibbons. Virology 1975, 67:335-343.

206. Lieber MM, Sherr CJ, Todaro GJ, Benveniste RE, Callahan R, Coon HG: Isolation from the Asian mouse Mus caroli of an endogenous type $\mathrm{C}$ virus related to infectious primate type $C$ viruses. Proc Natl Acad Sci USA 1975, 72:2315-2319.

207. Payne LN: Biology of avian retroviruses. In The Retroviridae. Volume 1. Edited by: Levy JA. New York: Plenum Press; 1992:299-404.

208. Qiu X, Swanson P, Luk KC, Tu B, Villinger F, Das Gupta J, Silverman RH, Klein EA, Devare S, Schochetman G, Hackett J Jr: Characterization of antibodies elicited by XMRV infection and development of immunoassays useful for epidemiologic studies. Retrovirology 2010, 7:68

209. Sakuma T, Tonne JM, Squillace KA, Ohmine S, Thatava T, Peng K-W, Barry MA, Ikeda Y: Early events in XMRV infection of wild-derived mouse, Mus pahari. J Virol.

210. Hartley JW, Rowe WP, Capps WI, Huebner RJ: Isolation of naturally occurring viruses of the murine leukemia virus group in tissue culture. J Virol 1969, 3:126-132.

211. Guenet $J$, Bonhomme F: Wild mice: an ever-increasing contribution to a popular mammalian model. Trends Genet 2003, 19:24-31.

212. Macholan M, Munclinger $P$, Sugerkova $M$, Dufkova $P$, Bimova B, Bozikova $E$, Zima J, Pialek J: Genetic analysis of autosomal and X-linked markers across a mouse hybrid zone. Evolution 2007, 61:746-771.

doi:10.1186/1742-4690-7-101

Cite this article as: Kozak: The mouse "xenotropic" gammaretroviruses and their XPR1 receptor. Retrovirology 2010 7:101. 